\section{Kidney \\ Blood Pressure \\ Research}

Review

\title{
Pathogenesis and Treatment of Chronic Kidney Disease: A Review of Our Recent Basic and Clinical Data
}

\author{
Yasuhiko Tomino \\ Division of Nephrology, Department of Internal Medicine, Juntendo University Faculty of Medicine, \\ Tokyo, Japan
}

\section{Key Words}

IgA nephropathy $\bullet$ Diabetic nephropathy $\bullet$ Peritoneal dialysis $\bullet$ Hemodialysis $\bullet$ Ultrasonography

\begin{abstract}
Chronic kidney disease (CKD) is a worldwide public health problem that affects millions of people from all racial and ethnic groups. At end of 2013, over 300,000 Japanese patients had maintenance dialysis therapy (JSDT). In Japan, the major causes of end stage kidney disease (ESKD) are chronic glomerulonephritis (particularly IgA nephropathy), type 2 diabetic nephropathy, and hypertensive nephrosclerosis. Hypertension is a major factor driving the progression of CKD to ESKD. Since many features of the pathogenesis of IgA nephropathy are still obscure, specific treatment is not yet available. However, efforts by investigators around the world have gradually clarified different aspects of the pathogenesis and treatment of IgA nephropathy. Today, around half of all diabetic patients in Japan receive medical treatment. Type 2 diabetic nephropathy is one of the major long-term microvascular complications occurring in nearly $40 \%$ of Japanese diabetic patients. The pathogenesis of diabetic nephropathy involves both genetic and environmental factors. However, the candidate genes related to the initiation and progression of the disorder are still obscure in patients with diabetic nephropathy. Regarding environmental factors, the toxicity of persistent hyperglycemia, reactive oxygen species, systemic and/or glomerular hypertension, dyslipidemia and complement are considered to play an important role. The first part of this review covers the pathogenesis of IgA nephropathy and type 2 diabetic nephropathy, and combines the clinicopathological findings in patients with our research on the ddY and KKA-y mouse models (spontaneous animal models for IgA nephropathy and diabetic nephropathy, respectively). In Japan, the major renal replacement therapies (RRT) are peritoneal dialysis (PD) and hemodialysis (HD). The second part of this review focuses on PD and HD. Based on our research findings from patients and as well as from animal models, we discuss strategies for the management of patients on PD and HD.
\end{abstract}




\section{Kidney Blood Pressure Research}

\section{IgA nephropathy}

IgA nephropathy (nephropathy with mesangial IgA and IgG deposits, the so-called Berger's disease in France) is the most common primary chronic glomerulonephritis in the world first described by J. Berger et al. in 1968 [1]. Histopathologically, IgA nephropathy is characterized by expansion of the glomerular mesangial matrix with mesangial cell proliferation and/or mononuclear cell infiltration. Glomeruli typically contain generalizeddiffuse granular mesangial deposits of IgA (mainly polymeric IgA1), IgG and complement 3 (C3). Thus, this disease is generally considered to be an immune-complex-mediated glomerulonephritis although the antigenic substances are still unknown. Clinically, patients with IgA nephropathy show microscopic- and macroscopic hematuria and/or proteinuria. Patients with advanced disease progress to renal hypertension, renal anemia and ESKD. Since the exact pathogenesis has not yet been established and no effective treatment exists for IgA nephropathy, a study of the clinical findings in patients and an examination of animal models can shed light on these open questions.

\section{Clinical manifestations}

The majority of patients show no symptoms, but occasionally there may be acute nephritic syndrome. The appearance of nephrotic syndrome, however, is relatively rare in Japan. The clinical course is generally gradual, but progression to renal hypertension, renal anemia and ESKD in patients with IgA nephropathy is not as rare as originally thought.

\section{Urinalysis and blood chemistry}

Urinalysis performed at least three times is required for the diagnosis of urinary abnormalities, and at least two of the tests should include microscopic examination of urinary sediments in addition to routine urinalysis. Patients with IgA nephropathy show microscopic- and macroscopic hematuria and/or proteinuria. Macroscopic hematuria is occasionally observed after upper respiratory infections including acute tonsillitis and/or pharyngitis. IgA nephropathy is frequently preceded by episodes of upper respiratory or gastrointestinal infections, which are presumed to have a viral or bacterial etiology. Many dysmorphic red blood cells (RBCs), various cellular casts and activated platelets in the urinary sediments are frequently observed in advanced stages of this disease [2].

There are no essential blood chemistry findings which are characteristic of this disease. However, serum IgA levels $>315 \mathrm{mg} / \mathrm{dL}$ have frequently been observed in adult patients with IgA nephropathy.

\section{Histopathological classification}

Among numerous histological grading systems for predicting renal outcome of IgA nephropathy, the Oxford classification of this disease identifies prognostic pathologic features, and provides substantial evidence that histological grading systems can be used to predict renal outcome of IgA nephropathy [3]. When developing a histological classification of IgA nephropathy, some issues need to be considered. One issue is whether the classification is based on a split system or a lumped system. The split system, such as that employed in the Oxford classification, groups patients according to the presence or absence of histological features with predictive values. With its emphasis on the qualitative aspects of the lesions, the split system-based classification, is more informative, but is time-consuming for routine clinical use. The lumped system relies on the proportion of glomeruli exhibiting histological lesions with predictive values. Lumped system-based classifications are simpler and more practical for routine clinical use, but there is the possibility that the importance of each lesion is overlooked. Another issue is the variability in the indications for renal biopsy. In some countries, asymptomatic individuals with microscopic hematuria are likely to undergo renal biopsy, whereas in other countries patients presenting with isolated hematuria or mild proteinuria are usually not indicated for biopsy, unless aggravated proteinuria or worsening of renal function develops. It should be noted that the cohorts included in the Oxford 


\title{
Kidney \\ Blood Pressure Research
}

classification did not include patients with very mild proteinuria or isolated microscopic hematuria as initial clinical presentations, since very mild forms (proteinuria of less than $0.5 \mathrm{~g} /$ day) of IgA nephropathy were excluded [3].

In Japan, the Special IgA Nephropathy Study Group of the Progressive Renal Diseases Study Committee organized by the Ministry of Health, Labor and Welfare conducted a multicenter retrospective case-control study on IgA nephropathy in 2004 to develop an evidence- and lumped-system-based clinicopathological classification of IgA nephropathy for predicting the long-term risk of progression to ESKD [4]. Two hundred and eighty-seven patients with a median follow-up of 9.3 years (range: 0.7-34.0 years) after renal biopsy were enrolled. During the follow-up, 49 patients (19\%) progressed to ESKD. Multivariate logistic regression analysis showed that the independent pathological variables predictive of progression to ESKD were global sclerosis, segmental sclerosis and fibrous crescents for patients who progressed to ESKD within 5 years after the biopsy, and global sclerosis and cellular/fibrocellular crescents for those who progressed to ESKD within 5-10 years after the biopsy. Four histological grades were established, i.e., histological grade (HG) 1, HG 2, HG 3 and HG 4, corresponding to $<25 \%, 25-49 \%, 50-74 \%$ and $>75 \%$ of glomeruli exhibiting cellular or fibrocellular crescents, global sclerosis, segmental sclerosis or fibrous crescents. Eleven (7\%) of the patients in HG 1, 12 (16\%) in HG 2, 13 (31\%) in HG 3 and 13 (68\%) in HG 4 progressed to ESKD. Multivariate logistic analysis revealed that the risk of progression to ESKD was significantly higher in the categories HG 2, 3 and 4 than in HG 1 (odds ratios: 2.4, 5.7 and 27.6 vs. 1.0). These findings indicate that our evidence- and lumped-systembased histological classification can identify the risk of disease progression and is useful for predicting long-term renal outcome in patients with IgA nephropathy.

Progressive factors

There are many factors that contribute to disease progression in patients with IgA nephropathy, including genetic background :

\author{
Summary of the Nationwide Survey of IgA Nephropathy in Japan \\ (Ministry of Health, Labor and Welfare, Japan, 2005). \\ Predictive factors after 10 years: \\ 1. Male \\ 2. Under 30 years old \\ 3. Diastolic hypertension \\ 4. Heavy proteinuria \\ 5. Mild hematuria \\ 6. Low serum albumin \\ 7. Elevated serum creatinine \\ 8. Impaired renal histopathology
}

The following section summarizes the role of complement activation, podocyte injury and mast cell infiltration in the interstitium $n$ patients with IgA nephropathy.

\section{Complement activation}

Earlier studies indicated that IgA per se activates the alternative pathway of complement, whereas more recent data have also showed activation of the lectin pathway in patients with IgA nephropathy. Roos et al. [5] reported contributions of both mannose-binding lectin (MBL) and L-ficolin in the progression of IgA nephropathy. The authors hypothesized that serum levels of complement components and regulatory proteins in patients with IgA nephropathy are correlated with the pathogenesis of the disease. My colleagues Onda et al. [6] clarified the variations in serum levels of complement components and complement regulatory proteins (CRPs) in patients with IgA nephropathy. It appears that hypercomplementemia occurs in the progression of IgA nephropathy and is regulated by an increase in CRPs. In particular, 


\section{Kidney Blood Pressure Research}

higher levels of serum C4 binding protein may indicate the severity of histological injury in this disease [6].

We focused on the fluctuations in serum C3 levels throughout the clinical course of the disease, and investigated the relationship between these fluctuations and clinical findings. A total of 122 IgA nephropathy patients were enrolled in our study. Serum C3 and other clinical markers were compared at the time of renal biopsy and at last follow-up $6.67 \pm$ 2.07 years). Patients were divided into three groups based on serum C3 levels: Group I with initial C3 levels below the mean -1 SD, which evolved into an increase at last observation; Group II with initial C3 levels more than the mean +1 SD, which evolved into a decrease at last observation; and Group III, with initial C3 levels more than the mean +1 SD, which evolved into an increase at last observation. The first and last levels of clinical markers were compared among the three groups. In those patients whose renal symptoms, including hematuria, proteinuria and estimated glomerular filtration rate (eGFR) improved, serum C3 levels were significantly increased at last observation ( $\mathrm{p}<0.05, \mathrm{p}<0.01, \mathrm{p}<0.01$, respectively). Age, total cholesterol (TC) and triglyceride (TG) levels in Group III were significantly higher than those in Group I. Group II showed a significant reduction of urinary protein. Groups I and II maintained renal function, but Group III showed a significant deterioration of renal function. The levels and fluctuations of serum C3 levels may reflect the disease activity and metabolic alterations in patients with IgA nephropathy [7].

At the time of renal biopsy, hypertension, dyslipidemia, hyperuricemia, and hypercomplementemia in the obese group (BMI: $23.1-31.9 \mathrm{~kg} / \mathrm{m}^{2}$ ) were more significant compared with those in the lean group (BMI: $15.6-20.2 \mathrm{~kg} / \mathrm{m}^{2}$ ) and/or middle group (BMI: $20.2-23.0 \mathrm{~kg} / \mathrm{m}^{2}$ ). In the obese group, the decrease in urinary protein excretion over five years was significantly delayed using a Log-Rank test. It appears that even slight obesity seems to be a prognostic risk factor in Japanese patients [8].

My colleagues Ohsawa et al. explored the significance of extraglomerular (Bowman's capsule and/or arteriole) C3 (ex-C3) deposits in IgA nephropathy [9]. One hundred and seventy patients with IgA nephropathy were divided into two groups: Group A ( $n=79)$, which comprised patients who did not have ex-C3 deposits, and Group B $(n=91)$, which comprised patients who had ex-C3 deposits. At the time of renal biopsy, Group B was characterized by a marked increase in diastolic blood pressure (BP), TC, TG and low-density lipoprotein (LDL)cholesterol compared to Group A. After four years, the eGFR in Group B was significantly worse than that in Group A. Upon examination by electron microscopy, the arteriolar dense deposits in Group B were observed to occur in significantly higher amounts than in Group A. One hundred and thirty-four patients underwent a three-year follow-up study after the intervention and were re-divided according to therapeutic factors as follows: 'conventional therapy', treatment with anti-hypertensive drugs and/or anti-platelet drugs, and 'aggressive therapy', as well as additional treatment with either tonsillectomy or corticosteroids. Patients treated with conventional therapy in Group B had significantly higher body mass index (BMI) and levels of C3 and 50\% hemolytic unit of complement (CH50) compared with the other groups. Aggressive therapy was significantly effective at urinary protein reduction in both Group A and Group B. Except for the patients who received aggressive therapy in Group A, the levels of eGFR gradually declined. It appears that IgA nephropathy patients who have ex-C3 deposits have worse clinical outcomes [9].

Another group of my colleagues, Kusaba et al. [10] have also found that electron-dense deposits (EDD) are often observed in areas other than the paramesangial areas in glomeruli. To compare electron microscopic findings with light microscopic findings and clinical data, we examined the renal biopsies from 178 patients with IgA nephropathy. Patients were divided into two groups: Group A (142 patients) had only paramesangial deposits, and Group $\mathrm{B}$ had deposits not only in paramesangial areas but also in other areas. All patients examined in our study had EDD in the glomerular paramesangial areas. Thirty-six patients were included in Group B. Cellular crescent formation in glomeruli and urinary protein in Group B were significantly higher than those in Group A $(p<0.01)$. Serum albumin and eGFR in Group B were significantly lower than those in Group A ( $p<0.05)$. The clinical characteristics 


\section{Kidney Blood Pressure Research}

of Group B showed a significant positive correlation with histological severity, as defined in the Japanese Clinical Guidelines on IgA nephropathy. In patients with a broad distribution of EDD, urinary protein excretion levels were significantly increased $(\mathrm{p}<0.05)$. Taken together, these results suggest that detailed observation of EDD distribution can have an impact on evaluation of the disease activity of IgA nephropathy [10].

\section{Podocyte injury}

The development of glomerulosclerosis in several human and experimental diseases is associated with podocyte injury. The number of podocytes per glomerulus may be a podocyte injury parameter that could provide prognostic information in patients with IgA nephropathy. Podocyte injury may be caused by apoptosis, necrosis, detachment from the glomerular basement membrane (GBM), or autophagy. It has also been speculated that deposition of IgA, IgG and C3 in the glomerular capillary walls and/or the presence of cytokines or reactive oxygen species (ROS) produced by resident glomerular cells may induce podocyte injury.

Lemley et al. [11] reported that podocyte loss, i.e. podocytopenia, is concurrent with increasing disease severity in patients with IgA nephropathy. They observed no corresponding correlation between the clinical indices of injury and the number of mesangial and endothelial cells in this disease. This finding is not surprising given that endothelial and mesangial cell damage is followed by regeneration. However, this is not the case with podocytes. Podocytes in adults do not undergo mitosis, and the only normal response to injury is cell hypertrophy. Thus, increased podocyte surface area reflects the extent of podocyte hypertrophy. In patients with severe disease, segments of the GBM become denuded. Direct contact between the naked portion of the GBM with the parietal epithelium of Bowman's capsule may lead to adhesion to Bowman's capsule and potentially, segmental sclerosis. My colleagues Hishiki and Shirato et al. [12] have reported that podocyte injury, i.e. reduction of the absolute number per glomerulus and increase of the glomerular surface area covered by one podocyte, are related to disease progression in patients with IgA nephropathy. Thus, podocyte injury may provide additional prognostic information in these patients [13].

Dendrin, a newly-identified component of the glomerular slit diaphragm, accumulates in the nucleus of injured podocytes in experimental glomerulonephritis. My colleagues Kodama and Asanuma et al. [13] investigated the existence of nuclear dendrin and the relationship between relocation of dendrin to the podocyte nucleus and disease progression in patients with IgA nephropathy. A positive correlation was observed between acute extracapillary changes and the number of dendrin-positive nuclei per glomerulus. The number of dendrin positive nuclei in renal biopsy specimens may therefore be useful for evaluating disease activity in IgA nephropathy patients.

\section{Mast cell infiltration in the interstitium}

Mast cells are derived from hematopoietic progenitors and migrate into inflammatory lesions. Human mast cells can be classified into two types according to their protease composition: those containing only tryptase (MCT) and those containing both tryptase and chymase (MCTC). MCT are involved in immunological responses, whereas MCTC appear to play a role in angiogenesis and tissue remodeling. In the normal kidney, mast cells are rarely found. However, more mast cells are present in the kidneys of IgA nephropathy patients. In particular, the MCTC subtype predominates over the MCT subtype in the interstitial lesions. Mast cells have been observed around but not within conglomerates of angiotensin II (AngII)-positive cells. The number of Ang-II positive cells has been correlated with MCTC and MCT in patients with IgA nephropathy with the most severe pathological changes. It appears that chymase-dependent Ang-II synthesis due to human mast cells may be involved in the inflammatory and fibrotic processes of IgA nephropathy [14]. 


\section{Kidney Blood Pressure Research}

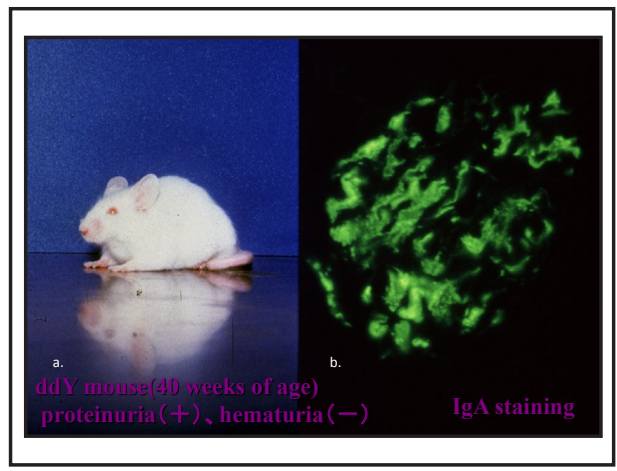

Fig. 1. The ddY mouse is a spontaneous animal model of human IgA nephropathy. A). The ddY mouse at 40 weeks of age (proteinuria + , hematuria -); B). Immunofluorescent IgA staining of a glomerulus in the ddY mouse.

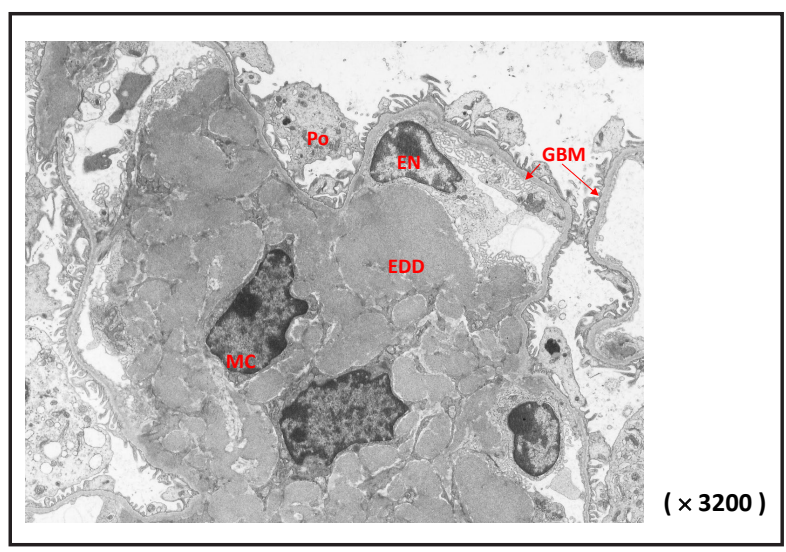

Fig. 2. Electron microscopic findings in a glomerulus of the ddY mouse. EDD: electron dense deposit, Po: podocyte, GBM: glomerular basement membrane, MC: mesangial cell, EN: endothelial cell.

\section{Molecular mechanisms in both the experimental and human settings}

Since IgA is an important immunoglobulin in the defense mechanisms against exogenous antigens in the mucosal system, it has been postulated that antigens might be located in the mucosal membranes of patients with IgA nephropathy. Although serum IgA levels are high in about $50 \%$ of IgA nephropathy patients, these levels do not always correlate with the degree of IgA deposition in the glomeruli or the severity of glomerular injury. The degree of renal tissue damage and progression of glomerulonephritis differs between individual patients.

\section{ddY mouse}

In the 40 years since IgA nephropathy was first reported, the cause of this disease had never been clarified. One of the main reasons for this was the lack of an appropriate animal model. The authors have established a spontaneous animal model for IgA nephropathy, the ddY mouse. Since then, the findings in the ddY mouse have been extrapolated towards the pathogenesis and treatment of patients with IgA nephropathy.

In 1985, Imai et al. [15] first reported that the ddY (Deutschland, Denken, Yoken) strain of mouse could serve as a spontaneous animal model for human IgA nephropathy. Imported from Germany before 1920, ddY mice have since then been maintained in Japan. These ddY mice exhibit mild proteinuria without hematuria and mesangioproliferative glomerulonephritis with glomerular IgA deposits. Marked deposition of IgA and C3 in the glomerular mesangial areas in association with an increase in the levels of macromolecular IgA appears in the sera of these mice as they age (Fig. 1a, 1b). EDD are apparent in the glomerular mesangial areas when observed by electron microscopy (Fig. 2). These immunopathological findings appear when the mice are over 40 weeks of age. Although the incidence of IgA nephropathy in ddY mice is highly variable, it appears that the clinicopathological aberrations besides hematuria in ddY mice resemble those in IgA nephropathy patients.

In my research division, sequential renal biopsies were performed on more than 360 ddY mice. IgA nephropathy occurred in about $30 \%$ of the mice by 20 weeks of age (early onset group) and in about $30 \%$ of the mice by 40 weeks of age (late onset group). IgA nephropathy did not occur in the remaining mice (quiescent group), see Suzuki H, et al. J Am Soc Nephrol 2005 [16]. When an "association study" on onset was performed on the early onset and quiescent groups of mice, multiple disease receptor gene loci were observed [16]. Since one of the loci was found to be homologous with the gene locus reported for human familial IgA nephropathy, at least some of these mice appear to be subject to the same genetic regulation as human IgA nephropathy. Therefore, ddY mice were considered to be useful as an animal model $[16,17]$. A genome-wide scan with 270 microsatellite markers identified 


\section{Kidney Blood Pressure Research}

three chromosomal regions on chromosomes 1, 9 and 10, which were significantly associated with glomerular injuries. The peak marker D10MIT86 on chromosome 10 is located in the region syntenic to human 6q22-23 which harbors IgAN1, the candidate gene responsible for familial IgA nephropathy [17]. In addition, the location of D1MIT16 in chromosome 1 was very close to the locus of the selectin gene, which is a known candidate for susceptibility to human IgA nephropathy. The three-group ddY mouse model is therefore a useful tool for identifying the susceptibility genes and for examining their roles in the pathogenesis of IgA nephropathy [16].

Treatment for IgA nephropathy in animal models

Steroid-liposome. Although glucocorticoids are effective for the treatment of IgA nephropathy patients with minor to moderate glomerular injuries, it is necessary to use large doses of the drug for long periods. This treatment regimen is associated with severe adverse effects such as diabetes, peptic ulcer and aseptic necrosis of the bones. Drug delivery systems (DDS) that can target drugs to specific body sites have long been sought, because they have the potential advantages of improved drug delivery, alongside reduction of adverse effects and potentially decreased drug doses required with targeted delivery to a specific cell type. Immunopathological studies were performed to determine whether glomerular injury in ddY mice was influenced by treatment with a newly developed liposome loaded with prednisolone phosphate (PSL-liposome) [18]. The novel synthesized cationic lipid 3, 6-dipentadeciroxy-1amizino-benzene (TRX-20) was employed to attain selective affinity towards the anionic cell surface and extracellular matrix (ECM) in glomerular mesangial lesions. We compared the immunopathologic findings between the PSL-liposome DDS against ordinary PSL treatment of IgA nephropathy in ddY mice. The mice were treated intravenously with $1.0 \mathrm{mg} / \mathrm{kg}$ of PSLliposome once a week from 45 to 61 weeks of age. Control mice were treated intravenously with $1.0 \mathrm{mg} / \mathrm{kg}$ of ordinary PSL once a week. Immunofluorescence studies revealed that the, mean intensity of IgA and C3 depositions in the glomeruli of PSL-liposome-treated ddY mice were markedly decreased compared to those of ordinary PSL-treated and untreated control ddY mice. Glomerular mesangial expansion in PSL-liposome-treated ddY mice was milder than that in ordinary PSL-treated ddY mice or untreated controls. Taken together, these results suggest that treatment with PSL-liposome is effective in improving glomerular IgA and C3 depositions and glomerular expansion in IgA nephropathy in ddY mice [18].

\section{Immunosuppressants}

Mizoribine, an immunosuppressant, was developed in Japan and has been shown to prevent the proliferation of lymphocytes in vitro and to possess immunosuppressive action in vivo. Since mizoribine also has a suppressive effect on antibody formation via direct inhibition of B-cell function, it has beneficial effects in patients with primary chronic glomerulonephritides, lupus nephritis, nephrotic syndrome and renal transplantation. My colleagues Shimizu et al. [19] have studied the clinical and immunopathological effects of mizoribine in ddY mice. The ddY mice were treated with $0.05 \mathrm{mg} / \mathrm{mL}$ (low dose) or 0.1 $\mathrm{mg} / \mathrm{dL}$ (high dose) of mizoribine for 35 weeks. Numbers of total $\mathrm{T}$ cells (CD3 ${ }^{+} \mathrm{T}$ cells), $\mathrm{CD}^{+} \mathrm{T}$ cells, $\mathrm{CD}^{+} \mathrm{T}$ cells and $\mathrm{CD} 11 \mathrm{~b}^{+}$cells amongst the spleen cells were measured by flow cytometry. Numbers of IgA-, IgG- or IgM-bearing B cells among the spleen cells were also counted. Immunohistopathological changes were examined by light microscopy and immunofluorescence. After 20 weeks of treatment, levels of urinary protein excretion in ddY mice treated with the high dose of mizoribine were lower than those treated with the low dose. Furthermore, expansion of glomerular mesangial areas in ddY mice treated with the high dose was significantly decreased compared to mice treated with the low dose or with the untreated controls. Numbers of B cells and IgA-bearing B cells among the spleen cells of ddY mice treated with the high or low dose of mizoribine were lower than in the untreated control mice. It appears that treatment with mizoribine may affect B cells, in particular the IgA-bearing B cells, and could improve glomerular injury related to IgA nephropathy in ddY mice [19]. 


\section{Kidney Blood Pressure Research}

\begin{tabular}{l|l}
\hline Kidney Blood Press Res 2014;39:450-489 \\
\hline DOI: $10.1159 / 000368458$ & (C) 2014 S. Karger AG, Basel
\end{tabular}

Publisned oninne: November 30, 2014

www.karger.com/kbr

Tomino: Clinicopathology of Chronic Kidney Disease (CKD)

Treatment with a monoclonal antibody to murine CD4 molecules

Immunopathological studies were performed to determine whether glomerular injury in ddY mice could be influenced by treatment with a monoclonal antibody (mAb) to murine CD4 molecules [20]. The ddY mice were initially treated with intravenous injections followed by weekly intraperitoneal injections of a CD4 mAb. Flow cytometry indicated a marked decrease in the number of $\mathrm{CD} 4^{+} \mathrm{T}$ cells. Immunofluorescence, studies showed that the mean intensity of IgA deposits in the glomerular mesangial areas and capillary walls of treated ddY mice was significantly lower than in saline-treated control ddY mice of comparable age. The extent of glomerular mesangial expansion in the treated ddY mice was milder than that in control mice. However, no significant differences in the levels of serum IgA, urinary protein excretion, and average number of intraglomerular cells were observed between treated and control ddY mice. It appears that although $\mathrm{CD}^{+}{ }^{+} \mathrm{T}$ cells control the amount of IgA deposits in glomeruli, other factors may be involved in the evolution of IgA nephropathy in ddY mice [20]. It is not known whether the increase observed in the number of intraglomerular cells in both treated and control ddY mice is due to resident glomerular cells or infiltrating mononuclear cells in the glomeruli. Our studies showed that the increased numbers of glomerular cells in ddY mice are positive for markers of Thy-1.2 (total T cells), CD8 (killer/suppressor T-cells) and CD11 (Mac-1, macrophages/monocytes), suggesting that the majority of these cells are likely to be infiltrating cells and glomerular mesangial cells. Several cytokines or growth factors such as IL-1, IL-6, TNF $\alpha$ and platelet-derived growth factor (PDGF) have also been shown to be involved in mesangial cell proliferation. Therefore, in addition to the effect of $\mathrm{CD}^{+} \mathrm{T}$ cells in modulating the amount of glomerular IgA deposits, it is likely that these other factors may also be involved in the progressive mechanisms of IgA nephropathy.

Bone marrow transplantation (BMT)

A previous report demonstrated that in a patient with IgA nephropathy and chronic myeloblastic leukemia, bone marrow transplantation (BMT) resulted not only in remission of leukemia but also in remission of IgA nephropathy [21]. Therefore, it has been suggested that in IgA nephropathy, the responsible cells may be localized in the bone marrow. Corroborating these findings, Imasawa et al. [22] have also reported that BMT from normal mice could attenuate the glomerular lesions in the HIGA (high serum IgA ddY) murine model of IgA nephropathy. Conversely, the glomerular lesions associated with IgA deposition could be reconstituted in normal recipient mice after receiving BMT from HIGA mice. These findings indicate that IgA nephropathy may also involve a dysregulation at the level of the stem cells. The ddY mouse is known as a spontaneous murine IgA nephropathy model, but the incidence of IgA nephropathy is highly variable. As described previously, my colleagues Suzuki et al. [16] observed that ddY mice could be classified into three groups, the early onset ( -20 weeks), late onset ( -40 weeks), and quiescent groups using serial renal biopsies that confirm glomerular lesions and IgA deposition. A genome-wide association study of the early onset and quiescent mice revealed that the susceptibility to murine IgA nephropathy is partly regulated by specific loci syntenic to the IGAN1 gene, also known as a candidate gene of human familial IgA nephropathy. These results indicated the suitability of the grouped ddY mouse model for examining the pathogenesis of IgA nephropathy.

Although the potential of bone marrow derived cells (BMC) to differentiate into glomerular cells has been discussed, the role of BMC in the kidney is still obscure. The mechanisms of glomerular immune-complex deposition and the role of BMC in the kidneys were examined using ddY mice. In 2007, my colleagues Suzuki et al. [23] reported that $\mathrm{BMC}$ are responsible for the induction of IgA nephropathy. BMT from the early onset ddY mice resulted in mesangioproliferative glomerulonephritis with mesangial IgA and IgG depositions in quiescent ddY mice recipients. In contrast, BMT from quiescent ddY mice resulted in the reduction of not only glomerular injury but also of mesangial IgA and IgG depositions in early onset ddY mice recipients. BMT from the early onset ddY mice resulted in progression of urinary albumin levels in quiescent ddY mice recipients, and also triggered a marked increase in urinary albumin levels in early onset ddY mice recipients. Thus, it 


\section{Kidney Blood Pressure Research}

appears that BMC, presumed to contain IgA producing cells, may initiate IgA nephropathy [23]. Conversely, when BMT was performed in ddY mice using the bone marrow of normal mice, glomerular IgA was eliminated and nephropathy dramatically improved.

\section{Abnormalities in the IgA molecule and mucosal immunity}

IgA molecules. In IgA nephropathy patients, serum IgA is characterized by many truncated 0-linked glycans with little galactose in the hinge region. In addition, there are decreased expression levels of $\beta 1,3$-galatosyltransferase and its molecular chaperone Cosmc that promote the galactosylation of IgA1 in peripheral B cells of IgA nephropathy patients. Therefore, attention has been focused on aberrant galactosylation of the IgA1 molecule as one of the causes of IgA nephropathy. It is possible that in IgA1 molecules with decreased galactosylation of the $\mathrm{O}$-linked glycans self-aggregation could occur under unstable conditions due to the hinge region structure and formation of an aggregate compound between the hinge region epitope and the IgA antibody [24-26]. This aberrantly galactosylated IgA1 is deposited in the glomerular mesangial regions by various mechanisms including binding with receptors, phagocytosis and electrical charge interactions. Experimentally, this aberrantly-galactosylated IgA1 is also known to promote mesangial cell proliferation.

\section{Mucosal immunity}

The main production site of IgA is the mucosa of the respiratory tract and intestine, and the first symptoms in the onset of IgA nephropathy are often symptoms suggestive of infections of the upper respiratory tract and gastrointestinal tract. Almost all IgA secreted from the mucosa is in dimeric or polymeric form, and the IgA deposited in the glomeruli of IgA nephropathy patients has the same properties, suggesting that mucosal immunity plays a central role in the pathogenesis of this disease.

IgA is secreted in the mucosa to prevent infiltration of pathogens or toxins through aggregation or neutralization. This IgA is polymeric and binds with secretory components (SC) or J-chains. Secretory IgA (SIgA) is also present in small amounts in the blood. There are several lines of evidence that support a role of SIgA of mucosal origin in the glomerular deposits of IgA. The fact that IgA nephropathy patients often show macroscopic hematuria after infections of the upper respiratory tract suggests that the onset of mucosal infections acts as a trigger. Recently, a correlation between hematuria and serum levels of SIgA1 has been reported [27]. Furthermore, J chains with IgA have been identified in the glomeruli of IgA nephropathy patients, and the IgA eluted from the glomeruli of resected kidneys of patients with relapsed IgA nephropathy after transplantation is polymeric SIgA1. Taken together, these findings underscore, the possibility that SIgA1 of mucosal origin plays an important role in glomerular deposition of IgA.

Toll-like receptors (TLR) are a family of pathogen pattern recognition receptors that recognize several different classes of pathogen-related structures and play a role in stimulating active immune defense mechanisms, particularly in innate immunity. Myeloid differentiation factor 88 (MyD88) is a common adaptor molecule required for signaling mediated by TLR. My colleagues Suzuki et al. [28] reported the relationship between TLR9 and the severity of renal injury in IgA nephropathy in ddY mice. MyD88 was identified as a candidate gene for the progression of renal injury in ddY mice. In one of our previous studies, ddY mice were housed under either conventional or specific pathogen-freeconditions. Expression of genes encoding TLR and the signaling molecule MyD88 were quantified by real-time reverse transcription-PCR in spleen cells isolated from these mice. Although the housing conditions did not affect the prevalence of IgA nephropathy, the severity of renal injury was higher in the conventionally-housed group. The ddY mice that had IgA nephropathy and were housed under conventional conditions had higher levels of TLR9 and MyD88 transcripts than the mice with IgA nephropathy that were housed under specific pathogen-free conditions. Moreover, nasal challenge with CpG-oligodeoxynucleotides (DNA), which are ligands for TLR9, further aggravated renal injury, led to strong Th1 polarization, and increased serum 


\section{Kidney Blood Pressure Research}

and mesangial IgA levels. It appears that activation of the TLR9/MyD88 pathway by common exogenous, (i.e. bacterial and/or viral antigens), may affect the severity of IgA nephropathy [23]. Thus, it was postulated that over-production of under-galactosylated IgA1 in the sera occurred due to common exogenous (i.e. bacterial and/or viral) infections in patients with IgA nephropathy.

Potential application of molecular findings from the evaluation of renal biopsies in patients with IgA nephropathy

It is thought that paracrine and/or autocrine stimulation of various growth factors and/or cytokines might influence glomerular cell proliferation and the expansion of mesangial matrices in patients with IgA nephropathy. Intercellular adhesion molecule-1 (ICAM-1), a glycoprotein of 90-110 kd, which belongs to the immunoglobulin superfamily, is a lymphokine, i.e. a IL-1, TNF and/or IFN- $\alpha$-inducible cell-surface molecule. ICAM- 1 is expressed on a restricted number of cells, namely vascular endothelial cells, macrophages, activated T cells and B cells, and melanoma cells. Using immunofluorescence, we examined patients with IgA nephropathy to determine whether the expression of ICAM-1 in glomeruli might reflect disease activity [29]. Glomeruli that showed increases of ICAM-1 expression had marked infiltration of lymphocytes and monocytes. The average number of these cells in glomeruli was higher in advanced stage patients, who also showed an increase of ICAM1 expression in glomeruli. It appears that the expression of ICAM-1 is closely linked to glomerular cell infiltration by lymphocytes and monocytes in patients with IgA nephropathy [29]. However, the actual distribution of ICAM-1 expression in glomeruli was distinct from that of IgA deposition in both the mild and advanced stages of IgA nephropathy. These results suggest that several cytokines and/or growth factors such as IL-1, IL-2, IL-6, TNF $\alpha$, and TGF- $\beta$ may be involved in glomerular mesangial cell proliferation and hyperproduction of ECM components such as fibronectin, type IV collagen and laminin.

\section{Clinical diagnosis of patients with IgA nephropathy}

We have already reported on the importance of four clinical markers in the diagnosis of patients with IgA nephropathy or in the differential diagnosis from other types of primary chronic glomerulonephritis: 1) more than five RBCs/high power field in urinary sediments, 2) persistent proteinuria (urinary protein levels of more than $0.3 \mathrm{~g} /$ day), 3) serum IgA levels above $315 \mathrm{mg} / \mathrm{dL}$ and 4) serum IgA/C3 ratio above 3.01. Patients with three or four clinical markers were easily diagnosed as having IgA nephropathy in our previous reports [2, 30]. Furthermore, urinary levels of IL-6 (interleukin-6: a T cell-derived lymphokine) and MCP-1 (monocyte chemoattractant protein-1: a chemotactic molecule for monocytes and T cells) were markedly increased in the advanced stage of IgA nephropathy with severe proliferative glomerular changes. Thus, the measurement of urinary IL- 6 and MCP- 1 is useful for evaluating prognosis and/or the degree of glomerular injury in patients with IgA nephropathy [31,32].

In IgA nephropathy patients, circulatory serum IgA1 and glomerular mesangial IgA1 deposits contain elevated amounts of galactose-deficient IgA1 (Gd-IgA1). We hypothesized that a fraction of Gd-IgA1 from the glomerular deposits may be excreted in the urine and thus may represent a disease-specific marker. In addition to aberrant glycosylation, IgA1 in the sera of patients with IgA nephropathy has been reported to be negatively charged. Abnormalities in IgA molecules other than aberrant glycosylation are also assumed to be associated with the onset of IgA nephropathy. There is increasing evidence that Gd-IgA1 and Gd-IgA1-containing immune complexes are important for the pathogenesis of IgA nephropathy.

In one of our previous studies, we assessed a novel noninvasive multi-biomarker approach in the diagnostic testing for IgA nephropathy. My colleagues Yanagawa and Suzuki et al. [33] compared serum levels of IgA, IgG, Gd-IgA1, Gd-IgA1-specific IgG and GdIgA1-specific IgA in 135 IgA nephropathy patients, 79 patients with non-IgA nephropathy CKD and 106 healthy controls. Serum was collected at the time of renal biopsy from all 


\section{Kidney Blood Pressure Research}

IgA nephropathy and CKD patients. Each serum marker was significantly elevated in IgA nephropathy patients compared to CKD patients $(p<0.001)$ and healthy controls $(p<0.001)$. While $41 \%$ of IgA nephropathy patients had elevated serum Gd-IgA1 levels, 91\% of these patients exhibited Gd-IgA1-specific IgG levels above the 90th percentile for healthy controls (sensitivity 89\%, specificity 92\%). Although up to 25\% of CKD patients, particularly those with immune-mediated glomerular diseases including lupus nephritis, also had elevated serum levels of Gd-IgA1-specific IgG, most IgA nephropathy patients had elevated levels of Gd-IgA1-specific antibody of both isotypes. Serum levels of Gd-IgA1-specific IgG were associated with renal histological grading. Furthermore, there was a trend towards higher serum levels of Gd-IgA1-specific IgG in IgA nephropathy patients with at least moderate proteinuria (more than $1.0 \mathrm{~g} / \mathrm{g} \cdot \mathrm{Cr}$ ), compared to patients with less proteinuria. Therefore, it can be concluded that serum levels of Gd-IgA1-specific antibodies are elevated in most IgA nephropathy patients, and their assessment, together with serum levels of Gd-IgA1, improves the specificity of the assays. Our observations suggest that a panel of serum biomarkers may be helpful in differentiating IgA nephropathy from other glomerular diseases [33].

\section{Patient management and prognosis}

Management of dietary salt and protein intake in educational short-term hospitalization. Prognosis of CKD including IgA nephropathy depends not only on treatment but also on dietary control. A low-salt diet is usually recommended to control BP since high salt intake is a major cause of increased BP. Long-term protein restriction is generally considered to reduce the levels of urinary protein and ameliorate glomerular injury in patients with IgA nephropathy. Thus, assessment of salt and protein intakes is very important in the management of IgA nephropathy. A thorough understanding of the relationship between IgA nephropathy and diet can help to improve patient compliance. My colleagues Yamaji et al. [34] and Kobayashi et al. [35] estimated the dietary intake of sodium ( $\mathrm{Na}$ ) and protein by measuring urinary $\mathrm{Na}$ and urea nitrogen excretion during educational hospitalization. Estimation of actual salt and protein intakes requires 24-hour urine collection. We performed short-term (7 days) educational hospitalization of 110 CKD patients including IgA nephropathy patients. Estimated salt and protein intakes at day 7 were decreased compared with those at day 2. Systolic and diastolic BP upon completion of hospitalization were significantly lower than those at baseline. This educational program may be effective for improving patients' knowledge, more specifically, on the efficacy of dietary control of protein intake and BP control by dietary salt restriction in CKD and IgA nephropathy patients [34, 35].

\section{Olmesartan: anti-hypertensive drug}

Angiotensin-converting enzyme (ACE) inhibitors and/or angiotensin-receptor blockers (ARB) induce a marked renoprotective effect in patients with IgA nephropathy. Combination therapy with an ACE inhibitor and an ARB was reported to induce a more pronounced decrease in proteinuria progression in normotensive patients with IgA nephropathy. However, caution should be exercised to avoid too large a decrease in BP. In Japan, the treatment of ACE inhibitor or ARB could not be used for normotensive patients due to restrictions at the national insurance level. We evaluated the antiproteinuric effects of olmesartan, one of the ARB, in normotensive patients with IgA nephropathy in a multicenter controlled trial supported by Daiichi Sankyo Co. Ltd. (Tokyo, Japan) [36]. Olmesartan was given to 25 patients for 16 weeks. The initial dose was $5 \mathrm{mg}$ and was increased stepwise to $10 \mathrm{mg}, 20 \mathrm{mg}$ and $40 \mathrm{mg}$. The change in urinary protein to creatinine ratio (PCR) was $-56.2 \%$. Creatinine clearance (Ccr) showed no changes throughout the study period. The BP average was 119/77 $\mathrm{mmHg}$ in the lead-in period, this decreased to $107 / 77 \mathrm{mmHg}$ at week 16. Upon completion of treatment with olmesartan, no correlation was observed between changes in urinary PCR and mean BP based on an investigation of dispersion diagrams. It appears that olmesartan monotherapy resulted in a robust reduction of urinary protein excretion in normotensive IgA nephropathy patients, suggesting that this effect is independent of its BP-lowering properties [36]. 


\section{Kidney Blood Pressure Research}

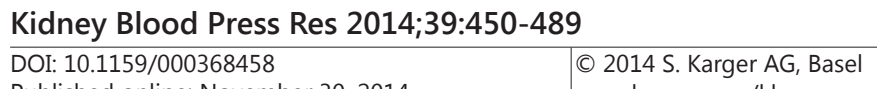

Publisned onIIne: November 30, 2014

www.karger.com/kbr

Tomino: Clinicopathology of Chronic Kidney Disease (CKD)

Benidipine: anti-hypertensive drug (calcium channel blockers)

Several subtypes of calcium channels, such as the $\mathrm{L}, \mathrm{T}$ and $\mathrm{N}$ channels, have been identified. Recent studies have revealed that inhibitory action on $\mathrm{N}$ - and T- type calcium channels is useful in the treatment of various renal diseases. Benidipine inhibits not only the L-type, but also the T-type and N-type calcium channels. Previous clinical studies involving hypertensive CKD patients have shown that benidipine has a more potent renoprotective effect compared to nifedipine and amlodipine, which are known to inhibit L-type calcium channels [37]. Calcium channel blockers (CCBs) such as amlodipine and nifedipine, which selectively block L-type calcium channels, can dilate afferent arterioles but not efferent arterioles in the glomeruli. Therefore, these drugs elevate the glomerular pressure, even though they increase the renal blood flow, and thereby induce exacerbation of renal dysfunction. It has recently been reported that CCBs capable of inhibiting N- and T-type calcium channels dilate the efferent arterioles. Possible factors involved in this effect include suppression of sympathetic activity mediated by inhibition of $\mathrm{N}$-type calcium channels and correction of renal hemodynamics mediated by inhibition of T-type calcium channels [38]. Clinical and preclinical studies have demonstrated that benidipine dilates both afferent and efferent renal arterioles, leading to reduction in the glomerular pressure and alleviation of proteinuria. The long-term antiproteinuric effect of benidipine has not been evaluated in detail in hypertensive CKD patients including those with IgA nephropathy [39]. In our recent study, benidipine ( $4 \mathrm{mg} /$ day) was administered to 65 previously untreated hypertensive CKD patients, or hypertensive CKD patients who did not achieve the target $\mathrm{BP}$ despite taking an ARB. If the target BP was not achieved by 2 weeks after the start of benidipine treatment, the dose was increased to $8 \mathrm{mg} /$ day. The patients were followed up for one year. The urinary $\mathrm{P} / \mathrm{Cre}$ ratio was evaluated before and after benidipine treatment. BP (systolic/diastolic) decreased from $154 \pm 19$ / $91 \pm 12 \mathrm{mmHg}$ before treatment to $134 \pm$ $16 / 78 \pm 10 \mathrm{mmHg}$ after one year of treatment $(\mathrm{p}<0.001)$. The urinary $\mathrm{P} / \mathrm{Cre}$ ratio decreased significantly from $2.21 \pm 2.47 \mathrm{~g} / \mathrm{g}$ creatinine $(\mathrm{g} / \mathrm{g}$ Cre) before treatment to $1.43 \pm 2.21 \mathrm{~g} / \mathrm{g}$ Cre after treatment $(\mathrm{p}<0.001)$. In both the untreated and ARB-treated groups, the BP and urinary $\mathrm{P} / \mathrm{Cre}$ ratio decreased significantly after one year of treatment. Our results indicate that benidipine treatment reduced the urinary P/Cre ratio in hypertensive CKD patients, with a greater percent decrease of the urinary $\mathrm{P} /$ Cre ratioseen in elderly patients, suggesting that benidipine may have more potent antiproteinuric effects in elderly hypertensive CKD patients including those with IgA nephropathy [39].

\section{Adrenocorticosteroid (prednisolone)}

In Japan, Kobayashi et al. [40] reported the efficacy of prednisolone (PSL) treatment in a 10-year follow-up of patients in the early stage (proteinuria of 1-2 g/day, Ccr of more than 70 $\mathrm{mL} / \mathrm{min}$ and a histological severity score of more than seven) of progressive IgA nephropathy. We performed a multicenter trial on PSL in Japanese patients with IgA nephropathy [41]. IgA nephropathy patients were divided into two groups: the PSL plus dilazep hydrochloride (an anti-platelet drug) group (33 patients) and dilazep hydrochloride alone group (36 patients). All patients showed Ccr levels of more than $70 \mathrm{~mL} / \mathrm{min}$. The mean levels of urinary protein excretion after one or three years of treatment were significantly lower than that before the start of treatment $(\mathrm{p}<0.05)$ in the PSL group. There were no significant differences in the mean levels of Ccr before or after one to four years of treatment in the PSL group. Therefore, it appears that combination therapy with PSL and dilazep hydrochloride was effective in patients the early stage of IgA nephropathy [41].

\section{Tonsillectomy with steroid pulse therapy}

The tonsils are mucosa-associated lymphoid tissues that come in close contact with extrinsic antigens, especially infectious antigens, and are the sites of initiation of immune responses. In recent years, there has been much focus on the tonsils. TLRs are a family of pathogen associated pattern recognition receptors that recognize several different classes of pathogen-related structures and trigger active defense mechanisms, particularly those 


\section{Kidney Blood Pressure Research}

related to innate immunity as described previously. Macroscopic hematuria is occasionally observed after acute tonsillitis and/or pharyngitis in patients with IgA nephropathy.

The clinical effects of tonsillectomy with steroid pulse therapy for the treatment of proteinuria and hematuria in patients with IgA nephropathy have been reported mainly from Japan $[42,43]$. Recently, we examined the relationship between expression profiles of tonsillar TLR9 or TLR9 single nucleotide polymorphisms (SNP) and the clinical effects of tonsillectomy with steroid pulse therapy. In IgA nephropathy patients, it was clear that there was a significant correlation between the TT genotype of the rs35410 SNP in TLR9 and histological severity [44]. In IgA nephropathy patients with high TLR9 expression levels in resected tonsils and a TT genotype, the therapeutic effects of tonsillectomy and steroid pulse therapy on hematuria and proteinuria were high, suggesting that exposure to extrinsic antigens in the mucosa (particularly in the tonsils) is important in the progression of IgA nephropathy via abnormal TLR9 activation. It appears that the treatment response of tonsillectomy to steroid pulse therapy may be correlated with tonsillar TLR 9 expression levels and the genotype of TLR9 SNP (rs352140) [44].

Kawamura et al. [45] performed a multicenter randomized controlled trial on concomitant tonsillectomy and steroid pulse therapy in IgA nephropathy patients. The objective of the study was to evaluate the effect of tonsillectomy in Japanese patients with IgA nephropathy. Patients with proteinuria and low serum creatinine (s-Cr) were randomized to receive either tonsillectomy combined with steroid pulse therapy (Group $A ; n=33$ ) or steroid pulse therapy alone (Group B; $n=39$ ). The primary endpoints were urinary protein excretion and the disappearance of proteinuria and/or hematuria. Within 12 months from baseline, the percentage decrease in urinary protein excretion was significantly larger in Group $A$ than in Group B $(\mathrm{p}<0.05)$. Logistic regression analyses revealed that the assigned treatment was a significant, independent factor contributing to the disappearance of proteinuria, but did not identify an independent factor for achieving the disappearance of hematuria or clinical remission. Although the antiproteinuric effect was significantly greater in the group that received tonsillectomy combined with steroid pulse therapy, the difference was marginal, and its impact on renal functional outcomes remains to be clarified [45].

Recent studies have shown that Gd-IgA1 plays an important role in the pathogenesis of IgA nephropathy. Recent clinical and experimental studies have also indicated that immune activation of tonsillar TLR9 may be involved in the pathogenesis of IgA nephropathy. In our recent study, IgA nephropathy patients $(\mathrm{N}=37)$ were divided into two groups according to response to therapy. In one group, serum Gd-IgA1 levels decreased after tonsillectomy alone ( $n=22,59 \%)$, whereas in the majority of the other group, these levels only decreased after the addition of steroid pulse therapy to tonsillectomy ( $n=15,41 \%)$. The former group showed significantly higher tonsillar TLR9 expression and better improvement in hematuria immediately after tonsillectomy compared to the latter group. This study indicated that the palatine tonsils are probably major sites of Gd-IgA1 producing cells. However, in some patients these cells may propagate to other lymphoid organs, which may partially explain the different responses observed to tonsillectomy alone. These findings may help to clarify some of the clinical observations that arise during the management of IgA nephropathy, and may highlight future directions for research [46].

\section{Prognosis}

In 2013, my colleagues Suzuki et al. [47] proposed a standardized set of criteria for defining IgA nephropathy remission as follows: three consecutive negative results over a 6-month period for urinary occult blood tests; urinary sediment RBC counts of less than 5/ high power field (hematuria remission) and urinary protein of less than $0.3 \mathrm{~g} / \mathrm{day}(\mathrm{g} / \mathrm{g} \cdot \mathrm{Cr}$ ) (proteinuria remission). Clinical remission is defined as cases with both hematuria remission and proteinuria remission, although this should be verified in future studies. They concluded that these remission criteria may be useful in predicting therapeutic outcome in patients with IgA nephropathy. 


\section{Kidney Blood Pressure Research}

About $70 \%$ of IgA nephropathy patients are revealed through abnormalities in annual urinalysis performed at schools or offices in Japan. In 1995, a Joint Committee of the Special Study Group on Progressive Glomerular Disease, Ministry of Health, Labor and Welfare of Japan found that the elapsed time was more than 3 years on average from estimated onset to the time of first medical consultation and subsequent diagnosis of IgA nephropathy by renal biopsy [48]. About 30\% and 5-10\% of IgA nephropathy patients develop ESKD within 15-20 years and 5 years, respectively. However, around $60 \%$ of these avoid ESKD. Notably, some spontaneously achieve natural remission or maintain a clinically stable condition without any treatment. Clinical markers for poor prognosis in this disease are as follows: 1) renal (glomerular and tubulointerstitial) histopathological changes, 2) heavy proteinuria, 3) renal dysfunction at the time of renal biopsy, 4) hypertension, 5) male gender, and 6) age of less than 30 years [49]. The significance of gene polymorphisms of the renin angiotensin aldosterone system (RAAS) for prognosis remains controversial in patients with IgA nephropathy.

\section{Conclusions}

It has been shown that 1) IgA1 with aberrant galactosylation increases in the blood and urine; 2) IgA1 with aberrant galactosylation is deposited in the glomerular mesangial areas; 3) BMCs may also be involved in the increase in IgA1 with aberrant galactosylation observed in the blood; 4) the cells responsible for the production of IgA are B cells that come into contact with antigens in the mucosa; and 5) the tonsils are important as one of the responsible lesions. Therefore, clarification of the mechanisms of aberrantly galactosylated IgA1 production that occur due to abnormal mucosal immunity will contribute towards clarifying the mechanism of onset of IgA nephropathy and will pave the way for the development of novel therapies. The results of future research are eagerly awaited.

\section{Type 2 Diabetic nephropathy}

Diabetic nephropathy is now increasing rapidly worldwide. In Japan, over the past two decades, the proportion of individuals with diabetic nephropathy with new-onset hemodialysis (HD) induction dramatically increased along with the increased numbers of patients with diabetes [50]. Type 2 diabetic nephropathy is a major cause of ESKD in patients with various renal diseases. According to the 2013 annual report by the Japanese Society of Dialysis Therapy (JSDT), the total number of dialysis patients was 314,180, and since 1998 the leading cause of ESKD became diabetes (43.8\%) instead of chronic glomerulonephritis (18.8\%). Around 30 to $40 \%$ of type 2 diabetic patients develop diabetic nephropathy despite strict blood glucose and/or BP control. Although familial clustering of diabetic nephropathy has been demonstrated in all the populations examined so far, marked differences exist in the magnitude of the risk for type 2 diabetic nephropathy in various racial groups. Epidemiological evidence strongly suggests that genetic susceptibility may play an important role in the development of type 2 diabetic nephropathy. More than $90 \%$ of the human genome sequence has been clarified by the human Genome Project. Thanks to new technologies, it is expected that genetic studies in this field will contribute towards understanding the factors that modulate genetic susceptibility. Indeed, numerous case-control studies have investigated the association between apolipoprotein E (APOE) polymorphisms and diabetic nephropathy in patients with types 1 and 2 diabetes. APOE is well known to have a polymorphism $(\varepsilon 2,3$ and $\varepsilon 4)$ in exon 4 , and has been considered a candidate gene susceptible to this complication, i.e. diabetic nephropathy [51]. This variant is thought to be involved in lipid metabolism in various diseases. Araki [51] has reported that the $A P O E$ polymorphism may be associated with genetic susceptibility towards the development and progression of diabetic nephropathy based on the results of relatively large-scale cohorts, family-based studies, and meta-analyses. 


\section{Kidney Blood Pressure Research}

The following sections provide an overview of the clinical and pathological features of type 2 diabetic nephropathy, our latest knowledge on the mechanisms of disease onset, followed by a discussion of patient management and prognostic factors.

\section{Clinical features and pathology}

Clinical manifestations. Worldwide, diabetic nephropathy is considered to be a major cause of ESKD in diabetic patients. Although renal biopsy is not performed on all patients with diabetes and the onset of type 2 diabetes is often unclear, clinical diagnostic criteria are usually used in Japan:

Clinical diagnosis of diabetic nephropathy

(Ministry of Health Welfare, Japan. 1991)

1) History of diabetes : more than five years

2) Presence of diabetic retinopathy and/or neuropathy

3) Persistent proteinuria or albuminuria

4) No severe hematuria and/or cellular casts

5) Increase of GFR and enlargement of kidneys:

occasionally (especially in the early stage)

Among the clinical findings listed above, the presence of diabetic retinopathy and/or neuropathy is a key parameter for clinical diagnosis. Persistent proteinuria or albuminuria are also important clinical markers. If diabetic patients exhibit severe hematuria and/or cellular casts, i.e. RBC casts, it is important to first rule out malignancies using cytology, ultrasonography and computerized tomography (CT) scans, and perform renal biopsies for differential diagnosis. An increase in GFR (Ccr) is observed at the onset of type 2 diabetes. Enlargement of the kidneys detected by ultrasonography or CT scan is also observed in the early stages of diabetes.

Based on these clinical features, the committees of both the Japan Diabetes Society (JDS) and Japanese Society of Nephropathy (JSN) have revised the new classification of diabetic nephropathy. The revised classification is adapted to the CKD classification (CGA classification) of the JSN 2012 (Table 1). Patients with diabetic nephropathy are classified into five stages as follows: Stage I (normoalbuminuria stage), showing normal or increased eGFR (more than $30 \mathrm{~mL} / \mathrm{min}$ of eGFR). Stage II (microalbuminuric stage) shows microalbuminuria (30-299 $\mathrm{mg} / \mathrm{g} \cdot \mathrm{Cr}$ of urinary albumin excretion, more than $30 \mathrm{~mL} / \mathrm{min}$ of eGFR). Stage III (macroalbuminuric stage) shows macroalbuminuria (more than $300 \mathrm{mg} / \mathrm{g} \cdot \mathrm{Cr}$ of urinary albumin excretion, more than $30 \mathrm{~mL} / \mathrm{min}$ of eGFR). Stage IV (renal failure stage) shows a decline in renal function (less than $30 \mathrm{~mL} / \mathrm{min}$ of eGFR). In Stage IV, patients also show uremic findings such as polyuria, oliguria, nocturia, renal anemia, hypertension, edema, and nausea and vomiting. Stage $\mathrm{V}$ is the last stage, necessitating dialysis.

\section{Albuminuria}

Microalbuminuria is major clinical sign in the early stages of diabetic nephropathy. Although significant structural changes are already apparent even at the stage of microalbuminuria, it is necessary to develop more sensitive markers for detecting the early stages of renal injury in patients with type 2 diabetic nephropathy. My colleagues Horikoshi et al. [52] have developed a highly sensitive and inexpensive method for testing urinary protein levels based on a dye-binding technique using Erythrosin B. The Erythrosin $B$ method showed an excellent correlation and equal sensitivity with the turbidimetric immunoassay. This sensitive method to measure urinary protein will be useful for the screening of microalbuminuria as the proteinuria in the early stages of kidney disease consists mostly of albumin. An HPLC assay which we reported as a sensitive method to detect microalbuminuria is also available, but costs the same amount as the turbidimetric immunoassay [53]. The Erythrosin B method represents a 70\% cost savings compared to the turbidimetric immunoassay [52]. 


\section{Kidney Blood Pressure Research}

Table 1. New classification of diabetic nephropathy in Japan (http://www.Jsn.or.jp/academicinfo/ckd/ dm_nephro.pdf), in Japanese)

\begin{tabular}{|c|c|c|c|c|c|c|}
\hline & & & & \multicolumn{3}{|c|}{$\begin{array}{l}\text { Persistent albuminuria categories } \\
\text { Description and range }\end{array}$} \\
\hline \multicolumn{2}{|c|}{$\begin{array}{l}\text { Original } \\
\text { disease }\end{array}$} & \multicolumn{2}{|c|}{ Albuminuria categories } & A1 & $\mathbf{A 2}$ & A3 \\
\hline \multirow{2}{*}{\multicolumn{2}{|c|}{ Diabetes }} & \multirow{2}{*}{\multicolumn{2}{|c|}{$\begin{array}{c}\text { Albumin-creatinine ratio } \\
\text { : ACR } \\
(\mathbf{m g} / \mathbf{g C r})\end{array}$}} & $\begin{array}{c}\text { Normo } \\
\text { albuminuria }\end{array}$ & $\begin{array}{c}\text { Micro } \\
\text { albuminuria }\end{array}$ & $\begin{array}{c}\text { Macro } \\
\text { albuminuria }\end{array}$ \\
\hline & & & & $<\mathbf{3 0}$ & $30-299$ & $\geq 300$ \\
\hline \multirow{6}{*}{ 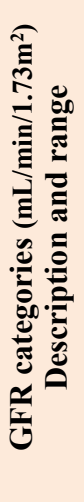 } & G1 & Normal or high & $\geqq 90$ & \multirow{4}{*}{$\begin{array}{c}\text { Stage I } \\
\text { (Prior DN) }\end{array}$} & \multirow{4}{*}{$\begin{array}{c}\text { Stage II } \\
\text { (Incipient DN) }\end{array}$} & \multirow{4}{*}{$\begin{array}{c}\text { Stage III } \\
\text { (Overt DN) }\end{array}$} \\
\hline & G2 & Mildly decreased & $60 \sim 89$ & & & \\
\hline & G3a & $\begin{array}{l}\text { Mild to moderately } \\
\text { decreased }\end{array}$ & $45 \sim 59$ & & & \\
\hline & G3b & $\begin{array}{l}\text { Moderately to severely } \\
\text { decreased }\end{array}$ & $30 \sim 44$ & & & \\
\hline & G4 & Severely decreased & $15 \sim 29$ & \multicolumn{3}{|c|}{ Stage IV (Renal failure) } \\
\hline & G5 & Kidney failure & $<15$ & \multicolumn{3}{|c|}{ Stage V (ESRD) } \\
\hline
\end{tabular}

\section{Urinary type IV collagen}

Type IV collagen is the major collagenous component of the ECM including the GBM and glomerular mesangial matrices. It is widely accepted that the accumulation of ECM components, including type IV and VI collagen, fibronectin and laminin, leads to glomerular sclerosis in various renal diseases including diabetic nephropathy. The increase in urinary type IV collagen levels in type 2 diabetic patients may be a consequence of an increased production and/or decreased degradation. Using a highly sensitive one-step enzyme immunoassay, we have demonstrated that the levels of urinary type IV collagen in type 2 diabetic patients with microalbuminuria was significantly higher than that in patients with normoalbuminuria [54]. We also indicated that the measurement of urinary type IV collagen concentrations can be a useful marker for detecting renal injury in type 2 diabetic patients, especially in the early stages as shown in our Asian Multicenter Clinical Trials [55].

\section{Cytokines and chemokines}

In 2002, my colleagues Tashiro et al [56] examined the correlation between the levels of urinary MCP-1 and IL-8, hyperglycemia, and renal injury in patients with type 2 diabetic nephropathy. High glucose may stimulate MCP-1 and/or IL-8 production and their excretion into the urine independently of disease stage or pathological lesions. It has been shown that IL-8 increases in the early stages of diabetic nephropathy, and MCP-1 increases in the advanced stages of diabetic nephropathy. Therefore, measurement of urinary MCP-1 and IL-8 levels may be useful for evaluating the degree of renal injury in patients with type 2 diabetic nephropathy [56].

\section{Mindin (spondin 2)}

Increasing evidence indicates that the inflammatory and immune response mechanisms may contribute significantly to the development and progression of diabetic nephropathy. 


\section{Kidney Blood Pressure Research}

Kidney Blood Press Res 2014;39:450-489

\begin{tabular}{l|l}
\hline DOI: $10.1159 / 000368458$ & (C) 2014 S. Karger AG, Basel
\end{tabular}

Published onlıne: November 30, 2014

www.karger.com/kbr

Inflammatory biomarkers could therefore be useful for the diagnosis or monitoring of diabetic nephropathy. Mindin (spondin 2) is a member of the mindin/F-spondin family of secreted ECM proteins. Previous studies showed that mindin is essential for initiation of the innate immune response and represents a unique pattern-recognition molecule in the ECM. My colleagues Murakoshi et al. [57, 58] demonstrated that urinary mindin expression in patients with type 2 diabetes was increased compared to healthy controls, reflecting the stage of diabetic nephropathy. These data indicate that urinary mindin may be a potent biomarker for the development of diabetic nephropathy.

\section{Serum cystatin $C$}

Creatinine clearance (Ccr) is usually used as a marker of GFR. However, it is generally considered that the levels of $\mathrm{Ccr}$ are $20 \%$ higher than those of GFR measured by inulin clearance (considered to be the gold standard for measurement of GFR). Cystatin C is a small non-glycosylated 13-kDa basic protein of the cystatin superfamily of cystein protease inhibitors, which are produced by all nucleated cells [59]. In 2002, my colleagues ShimizuTokiwa et al. [60] determined the relationship between the levels of serum cystatin $C$ or serum creatinine and the grade of $\mathrm{Ccr}$ in patients with various glomerular diseases. In this study, an increase in serum cystatin C levels occurred earlier than that of serum creatinine in such diseases. It appears that the levels of serum cystatin $\mathrm{C}$, rather than serum creatinine, may provide an early prognostic marker of patients with various glomerular diseases. We also examined the relationship between the levels of serum cystatin $C$ or serum creatinine and the grade of Ccr in patients with IgA nephropathy and diabetic nephropathy [60-62]. It was shown that the mean levels of serum cystatin $C$ in the macroalbuminuric stage without renal dysfunction were significantly higher than those in the normoalbuminuric or microalbuminuric stages. The mean levels of serum cystatin $\mathrm{C}$ in the macroalbuminuric stage with renal dysfunction (less than $60 \%$ of Ccr) or the renal failure stage (less than $30 \%$ of Ccr) were also significantly higher than those in the normoalbuminuric stage in type 2 diabetic nephropathy. Taken together, these findings suggest that the levels of serum cystatin $\mathrm{C}$ may be indicative of the early stages of type 2 diabetic nephropathy prior to renal biopsy [62].

\section{TNF receptors}

Chronic inflammation promotes the progression of diabetic nephropathy. However, the role of tumor necrosis factor (TNF) remains unclear. TNF $\alpha$ is a functional 26-kDa homotrimeric type II transmembrane protein [63]. It is an important proinflammatory cytokine that is expressed by a wide variety of cells, including monocytes, macrophages and $\mathrm{T}$ cells, fat cells and endothelial cells. The Joslin group from the US has reported that serum concentrations of soluble TNF, TNF receptor 1 (TNFR1), and TNFR2 are possible biomarkers for predicting GFR loss in patients with a variety of stages of diabetic nephropathy, as well as with both types 1 and 2 diabetes. My colleagues Gohda et al. [64] have reported that the concentrations of TNFRs strongly predict early and late renal function loss in both type 1 and 2 diabetes, independently of classical risk factors such as glomerular filtration rate (GFR) and albuminuria. Type 2 diabetic patients with proteinuria and TNFR1 levels in the highest quartile had a nearly $80 \%$ cumulative incidence of progression to ESKD after 12 years of follow-up, whereas the rate of progression to ESKD was less than $20 \%$ in those with TNFR1 levels in the lowest 3 quartiles $[63,64]$. Moreover, the concentration of TNFRs also predicted cardiovascular and all-cause mortality, but these effects were smaller than those observed for ESKD.

Recently, we have examined whether TNF $\alpha$ inhibition with a soluble TNFR2 fusion protein, etanercept, could improve the early stages of diabetic nephropathy in the KKAy mouse, a model of type 2 diabetes (details are described later) and also to investigate which TNF pathway (TNFR1 or TNFR2) is predominantly involved in the progression of this disease. It appears that etanercept may improve the progression of the early stages of diabetic nephropathy predominantly through inhibition of the anti-inflammatory actions of the TNF $\alpha$-TNFR2 pathway [65]. 


\section{Kidney \\ Blood Pressure Research}

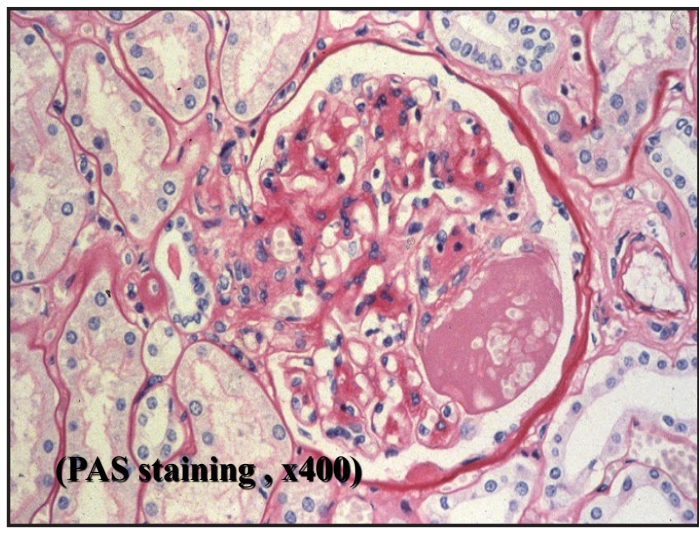

Fig. 3. An exudative type of diabetic nephropathy (PAS staining, x400). Glomerular exudative lesion, capsular drop in Bowman's capsule and extraglomerular arteriolar hyalinosis are seen in this figure.

\section{Kidney Blood Press Res 2014;39:450-489}

\begin{tabular}{l|l}
\hline DOI: $10.1159 / 000368458$ & (C) 2014 S. Karger AG, Basel
\end{tabular}

Published onlıne: November 30, 2014

www.karger.com/kbr

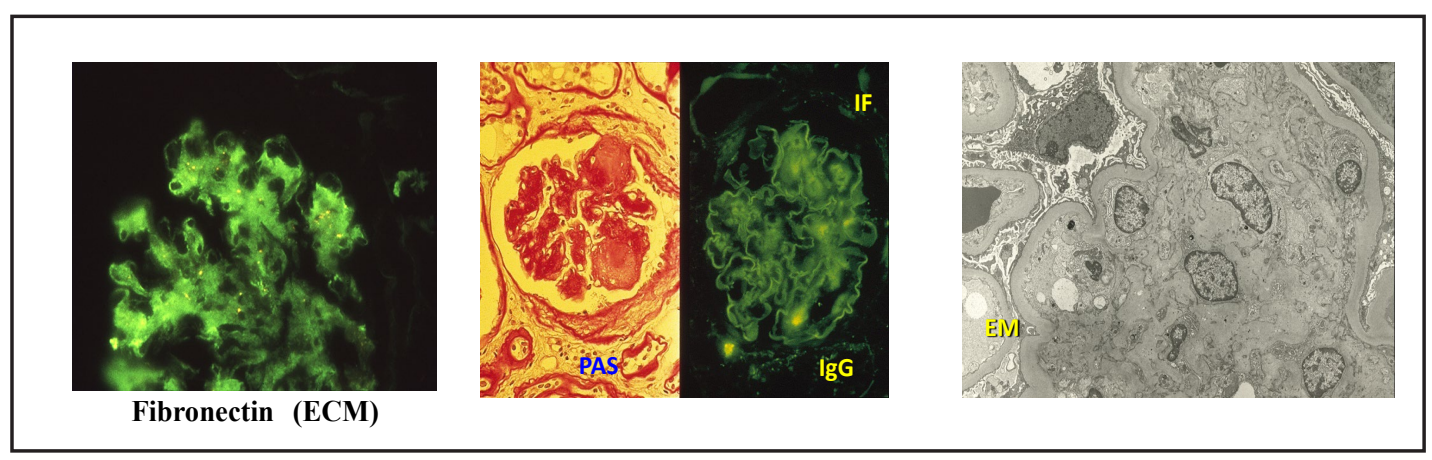

Histopathological classification

A conclusive diagnosis of type 2 diabetic nephropathy is performed by renal biopsy. In diabetic nephropathy patients, the histopathological findings are as follows: (a) thickening of the GBM, (b) glomerular enlargement, (c) diffuse expansion of glomerular mesangial matrices, (d) segmental nodular glomerular sclerosis, and (e) hyalinosis of both the glomerular afferent and efferent arterioles. Capsular droplets in the Bowman's capsules and exudative lesions are also observed in patients with diabetic nephropathy (Fig. 3). Global glomerular sclerosis and tubulointerstitial fibrosis are observed after the appearance of these pathological findings (Fig. 4).

Fig. 4. Histopathology of type 2 diabetic nephropathy. These figures indicate that glycosylated components (CML) and IgG may stimulate the production of extracellular matrix (ECM) components such as fibronectin, and induce nodular lesions in glomeruli. Mesangial expansion, cell proliferation and GBM thickening are observed in electron microscopy.

\section{Progressive factors}

The pathogenesis of diabetic nephropathy appears to be multifactorial. Several genetic and environmental factors likely contribute to its development and progression, see Friedman, NDT, 1999, [66]. Diabetes induces the formation of advanced glycation end products (AGEs), which can alter the function of proteins and stimulate pathological cellular responses via AGE receptors. Increasing levels of AGEs and their accumulation in diabetic kidneys correlate with the development of diabetic nephropathy [67]. Accumulation of AGEs in the ECM can alter both matrix-matrix and cell-matrix interactions involved in the pathogenesis of diabetic glomerulosclerosis. The binding of AGE proteins to their receptors on glomerular mesangial cells stimulates insulin-like growth factor (IGF)-I, -II, PDGF and TGF- $\beta$, which in turn modulate the production of ECM components in the glomerular mesangial matrices [68]. AGEs, including glycoxidation or lipoxidation products such as $\mathrm{N} \varepsilon$-(carboxymethyl) lysine, pentosidine, and malondialdehyde-lysine, are found to accumulate in the expanded glomerular mesangial matrices and thickened GBM of early diabetic nephropathy, and in the nodular lesions of advanced disease, suggesting their active participation in glomerulosclerosis $[69,70]$.

Reactive oxygen species (ROS) are thought to be among the key factors in the progression of diabetic nephropathy. Superoxide dismutase, glutathione peroxidase and catalase are 


\section{Kidney \\ Blood Pressure Research}

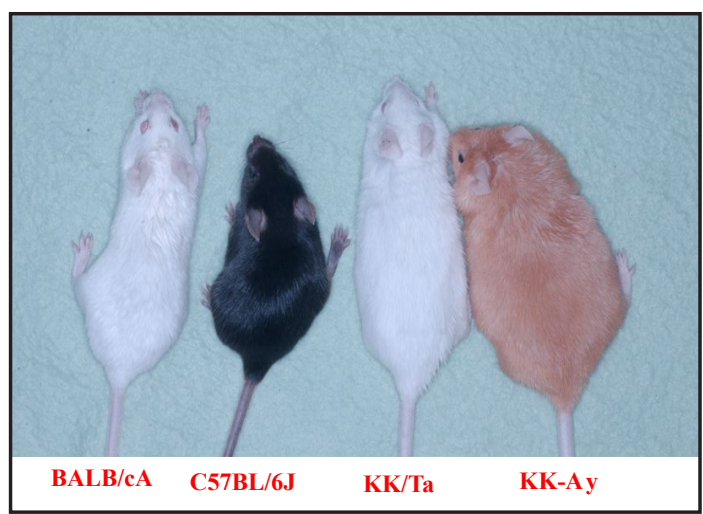

Fig. 5. Spontaneous mouse models for diabetic nephropathy, the KK/Ta and KK-Ay mice (shown alongside the BALB/CA and C57BL/6J non-diabetic control mice).

known markers of macrophages and tubular epithelial cells, including CD68, and CD163. CD68 (macrophage)-positive cells showed brush borders on the cell membrane and some of the cytokeratin-positive tubular cells also expressed CD163 (a member of the scavenger receptor superfamily) in mirror sections. Tubular CD68-positive cells were also positive for nitrotyrosine, gp91(phox) and Rac 1. Stimulation with crude bovine serum albumin (BSA), containing free fatty acids, induced CD68 expression in a dose- and time-dependent manner in the cultured mProx; however, this effect was not seen with pure BSA. These findings confirmed that tubular epithelial cells have the capacity to transdifferentiate into CD68positive macrophage-like cells, which may be linked to oxidative stress [71].

Cross-sectional studies of patients from the Diabetic Control and Complications Trial/ Epidemiology of Diabetic Investigations and Complications study group revealed that high levels of TG, LDL cholesterol, TC, and ApoB are associated with albuminuria [73]. Toyama et al. [74] summarized that dyslipidemia may be one of the potential risk factors for loss of renal function in healthy subjects. Long-term follow-up studies are needed to demonstrate the causal relationships between dyslipidemia and ESKD in diabetic nephropathy.

\section{Molecular mechanisms from in vivo experimental models and the clinical setting}

$K K$-Ay mouse. We established a spontaneous animal model for type 2 diabetic nephropathy (Fig. 5). In type 2 diabetic nephropathy, glomerular structure has been studied less extensively although this form of diabetes is a more common cause of ESKD. There have been many reports using various models of type 2 diabetes. The KK/Ta mouse, one of the type 2 diabetic nephropathy mouse models, was established from a Japanese native mouse strain via inbreeding by Kondo et al. in 1957 [75]. Male KK/Ta mice are generally considered to be a polygenic disease model and spontaneously exhibit type 2 diabetes associated with hyperglycemia including high levels of HbA1c, hyperinsulinemia, mild obesity and microalbuminuria. Since the phenotypic characteristics of KK/Ta mice are not especially pronounced, the KK-Ay mouse was established by Nishimura et al. in 1969 [76]. This mouse was produced by transfer of the yellow obese gene ( $A^{y}$ allele) into the KK/Ta mouse.

Morphometric analysis of the KK-Ay mouse has contributed greatly to our understanding of diabetic nephropathy. In 2006, we reported that the pathological changes in the glomeruli of KK-Ay mice were consistent with those in the early stages of human diabetic nephropathy [77]. The KK-Ay mouse, especially in terms of histopathological findings, is considered to be a suitable animal model for type 2 diabetic nephropathy. The urinary albumin/creatinine ratio (ACR) of KK-Ay mice was significantly higher than that of non-diabetic BALB/cA mice at all time points $(p<0.001)$. The levels of body weight in both KK-Ay and BALB/cA

(AOE) found in mammalian organs, and they defense mechanisms. In 2001, my colleagues Shou et al. [71] reported that control of systemic BP might improve intrinsic glomerular AOE activities, glomerular hyperfiltration, and glomerular expansion
in streptozotocin (STZ)-induced diabetic hypertensive rats (SHR). The improvement in glomerular AOE activities was also observed by control of blood glucose using insulin in
diabetic SHR. My colleagues Tanaka et al. [72] examined the process of transdifferentiation from tubular epithelial cells to macrophage(PAN) nephrotic rats and cultured murine
(PA) cells using puromycin aminonucleoside proximal tubular epithelial cells (mProx). The authors evaluated the expression of

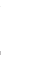
. 


\section{Kidney Blood Pressure Research}

Kidney Blood Press Res 2014;39:450-489

\begin{tabular}{l|l}
\hline DOI: 10.1159/000368458 & (c) 2014 S. Karger AG, Basel
\end{tabular}

Published onlIne: November 30, 2014

www.karger.com/kbr

Tomino: Clinicopathology of Chronic Kidney Disease (CKD)

mice increased gradually after 8 weeks of age. These levels in KK-Ay mice, however, were significantly higher than those in BALB/cA mice $(\mathrm{p}<0.001)$. The levels of HbA1c in KK-Ay mice were also significantly higher than those in BALB/cA mice $(\mathrm{p}<0.001)$. No significant changes were observed at the levels of systolic, diastolic and mean BP between KK-Ay and BALB/cA mice at 8 and 20 weeks of age. Overall, the diabetic phenotype in the KK-Ay mouse is more severe than that in the KK/Ta mouse [77].

Using quantitative trait locus analysis, my colleagues Aoki et al. [78] searched for candidate loci for albuminuria. Their findings indicated a significant linkage to chromosome 9 (LOD: 3.8) in mice at 20 weeks of age. This locus was different compared to the loci associated with other diabetic related phenotypes such as HbA1c and BW, suggesting that the phenotypes of diabetes and nephropathy are controlled by diverse responsible genes. From a large meta-analysis, Mooyaart [79] identified 24 genetic variants in 16 genes which are most likely to be associated with diabetic nephropathy patients.

Development of glomerulosclerosis in several human disorders and experimental disease models is associated with podocyte injury. The number of podocytes per glomerulus may be a podocyte injury parameter that could provide prognostic information in patients with diabetic nephropathy. Indeed, progressive diabetic nephropathy is associated with a reduction in the number of podocytes per glomerulus. The remaining podocytes are obliged to grow and extend their foot processes to maintain coverage of the same area. Macedo et al. [80] reported that control of hyperglycemia prevented GBM thickening in early and late (12 months) alloxan diabetic nephropathy and also prevented a reduction in the number of podocytes. We previously reported that podocyte injury might provide additional prognostic information in patients with IgA nephropathy, using renal biopsy tissues and the diabetic KK-Ay mice $[12,81]$. In light microscopy examinations, diffuse expansion of glomerular mesangial matrices was observed in diabetic KK-Ay mice. Sclerosed lobules with several homogenous periodic acid-Schiff (PAS) positive hyaline caps were observed at 20 weeks of age. A significant change in the glomerular area was observed among diabetic KK-Ay mice, KK/Ta mice and non-diabetic BALB/cA mice (KK-Ay vs BALB/cA: $\mathrm{p}<0.001$, KK/Ta vs BALB/ cA: $\mathrm{p}<0.01$ ). Mean podocyte numbers per glomerulus (NG pod) in diabetic KK-Ay mice (mean \pm SD: $6.73 \pm 1.78$ ) and KK/Ta mice (mean \pm SD: $5.94 \pm 2.46)$ were significantly lower than those in non-diabetic BALB/cA mice (mean \pm SD: 8.81 \pm 2.37 ) (KK-Ay vs BALB/cA: $p<0.05$, KK/ Ta vs BALB/cA: $\mathrm{p}<0.01$ ). Mean number of podocytes per $1000 \mu \mathrm{m}^{2}$ of glomerular area in diabetic KK-Ay mice and KK/Ta mice were also significantly lower than that in non-diabetic BALB/cA mice $(\mathrm{p}<0.01)$. The general mechanisms of podocyte loss are thought to occur via detachment of intact podocytes from the GBM due to necrosis, apoptosis and/or autophagy.

In diabetic nephropathy patients, there is no evidence of necrosis and no direct evidence for apoptosis as a major mechanism of podocyte loss. However, the apoptosis of podocytes has been determined in cell cultures. My colleagues Gu et al. [82] reported that MCP-1 was induced by AGEs and $\mathrm{N}(\varepsilon)$-carboxymethl-lysine (CML) in differentiated podocytes. It is speculated that the MCP-1/cysteine-cysteine chemokine receptor 2 (CCR2) system is involved in the apoptosis of podocytes in diabetic nephropathy. The detachment of intact podocytes from the GBM has been reported in Japanese diabetic patients. Nakamura et al. [83] indicated that the podocytes in urine samples may be a useful marker of disease activity in patients with diabetic nephropathy. The excretion of podocytes into the urine (podocyte loss) and subsequent hypertrophy may reflect disease activity in glomerular disease. Podocytes in adults do not undergo mitosis. Normally the only way to respond to injury is by cell hypertrophy. Thus, the increased podocyte surface area would reflect the extent of podocyte hypertrophy.

AGEs and TGF- $\beta$ protein appeared to be localized in the glomerular mesangial areas. AGE and TGF- $\beta$ products have been implicated in the pathogenesis of human diabetic nephropathy. We reported that KK-Ay mice exhibited type 2 diabetes and diabetic nephropathy from 8 to 20 weeks of age [77]. In PAS and PAM staining of specimens from KK-Ay mice, we observed segmental sclerosis in some glomeruli at 20 weeks of age.Immunohistochemical studies revealed that AGE and TGF- $\beta$ were especially pronounced in the glomerular mesangial areas. 


\section{Kidney Blood Pressure Research}

Patient management and prognosis

Despite the successful application of lifestyle changes, metabolic control, and BP control using ACE inhibitors and ARB, residual renal risk remains very high, leaving the diabetic population with a clear need for novel treatments. It is anticipated that some of the newer agents that are currently the focus of clinical trials will ultimately enable us to slow the progression and eventually improve the prognosis of this devastating disease.

\section{Effect of exercise}

Lifestyle modification, especially appropriate exercise, is recommended for the management of type 2 diabetic nephropathy through improvements of metabolic risk factors such as BP, blood glucose, plasma lipids, and oxidative stress markers. There are several mechanisms for the renoprotective effects of exercise in diabetic nephropathy. In general, exercise training ameliorates renal function by improving metabolic factors such as plasma lipids, blood glucose, BP, and BW. It is also known to improve renal histology without altering metabolic factors. Boor et al. [84] demonstrated that exercise training reduced AGEs in both serum and kidney tissues of obese Zucker rats, an animal model of type 2 diabetes, without altering inflammatory biomarkers or metabolic factors. On the other hand, appropriate exercise also consumes considerable amounts of oxygen, leading to the production of high levels of ROS. There is also evidence that ROS and high glucose exposure contribute to podocyte apoptosis in experimental diabetic nephropathy. My colleagues Ishikawa et al. [85] clearly demonstrated that exercised mice showed attenuated renal expression of MCP-1 and reduced infiltration of macrophages in the kidneys. We demonstrated that exercise training improved urinary N-acetyl-beta-D glucosaminidase (NAG) levels as well as the change rate of urinary ACR, independent of BW and glycemic status in the kidneys of KK-Ay mice, although moderate-intensity exercise increased the expression of HIF- $1 \alpha$ in the kidneys. In our study, no significant changes were observed in the levels of Ccr between sedentary KK-Ay and exercised KK-Ay mice. Therefore, it is possible that the decrease of urinary ACR was not due to the reduction of renal blood flow (RBF)/GFR, but more likely due to the effect of exercise.

It is thought that appropriate exercise increases anti-oxidant enzymes, although excessive exercise causes inflammation, increases oxidative stress associated with ROS, and decreases the RBF and GFR. In our study, both types of exercises decreased the levels of urinary 8-OHdG levels, a marker of oxidative stress. However, contrary to our expectation, low-intensity exercise was more effective than moderate-intensity exercise in terms of renal function [86]. Further investigation is required to determine the appropriate exercise intensity. It appears that low-intensity exercise attenuates the progression of early diabetic nephropathy without affecting renal ischemia. Reductions in the rate of urinary ACR change, urinary NAG, and maintained podocyte numbers, with parallel improvements in oxidative damage and chronic inflammation, might be related to the beneficial effects of exercise in diabetic nephropathy. However, attention should be paid to renal ischemia even though albuminuria has improved in patients with diabetic nephropathy.

\section{Age inhibitors}

Non-enzymatic glycation has been implicated in the pathogenesis of diabetic nephropathy. There are multiple pathways for the formation of AGEs, including $\mathrm{N}$-(carboxymethyl) lysine (CML), $\mathrm{N}$-(carboxyethyl) lysine and pentosidine, from glucose, products of the antioxidation of glucose, Schiff bases and Amadori products. The presence of AGEs is closely related to hyperglycemia and their pathobiochemistry could explain diabetic nephropathy. Specific AGEs, such as CML, are major products of glycoxidation reactions. In the ongoing effort towards reducing AGEs, many compounds have been reported as AGE inhibitors, such as aminoguanidine, phenacyl thiazolium bromide, 2-isopropylidenehydrazono-4-oxothiazolidine-5-yl-acetanilide(OPB-9195),2,3-diaminophenazine, vitamin C, vitamin E, ARB and pyridoxamine. Amongst these compounds, pyridoxamine has been shown to ameliorate lipid peroxidation and insulin resistance in KK-Ay mice. Pyridoxamine was introduced by Khalifah et al. [86] as an inhibitor of AGE formation from Amadori products. Degenhardt et 


\section{Kidney Blood Pressure Research}

\begin{tabular}{l|l}
\hline Kidney Blood Press Res 2014;39:450-489 \\
\hline DOI: $10.1159 / 000368458$ & (C) 2014 S. Karger AG, Basel
\end{tabular}

Publisned oninne: November 30, 2014

www.karger.com/kbr

Tomino: Clinicopathology of Chronic Kidney Disease (CKD)

al. [87] reported that pyridoxamine inhibited AGE formation and retarded the development of diabetic nephropathy in STZ-treated rats, an animal model for type 1 diabetes.

In 2007, my colleagues Tanimoto et al. [88] reported the prevention of the development of type 2 diabetic nephropathy in KK-Ay mice by pyridoxamine (K-163, Vitamin B), an AGE inhibitor. Pyridoxamine, especially at a dose of $400 \mathrm{mg} / \mathrm{kg}$ BW per day, improved levels of the urinary ACR, fasting serum TG and 3-deoxyglucosone (3DG) in KK-Ay mice. CML and nitrotyrosine accumulation in glomeruli were also decreased. TGF- $\beta 1$ and laminin- $\beta 1$ messenger RNA expression in the kidneys were also significantly lower in treated mice compared to the controls. These effects of pyridoxamine were related to improvement of CML and nitrotyrosine accumulation in the kidneys by anti-AGE and/or antioxidant effects [88]. Another group of my colleagues, Murakoshi et al. [89] studied the pleiotropic effects of pyridoxamine on diabetic complications in KK-Ay mice via its effects on CD36 expression. CD36 is an $88-\mathrm{kDa}$ membrane glycoprotein belonging to the class B scavenger receptor family of cell surface proteins, which possess one long extracellular loop between the two transmembrane domains. CD36 binds many ligands including collagen, oxidized low density lipoprotein, native lipoproteins, oxidized phospholipids, and long-chain fatty acids [88]. Pyridoxamine decreased the levels of serum TG, especially VLDL, and fasting serum insulin. Accumulation of malondialdehyde, an advanced lipoxidation end product, in the pyridoxamine treated group was significantly lower than that in thetreated group. CD36 accumulation and mRNA expression in the kidneys and adipose tissues of the treated group were significantly higher compared to the untreated group. In conclusion, treatment with pyridoxamine ameliorated lipid peroxidation and insulin resistance in KK-Ay mice. The pleiotropic effects of pyridoxamine were related to modulation of CD36 expression in the kidneys and adipose tissues [89].

\section{Statins}

The 3-hydroxy-3-methylglutaryl-coenzyme A (HMG-CoA) reductase inhibitors (statins) have multiple effects on cardiovascular, cerebrovascular, and microvascular diseases independent of their cholesterol lowering effect. Statins also have beneficial effects on kidney disease, including diabetic nephropathy. Previous in vitro and in vivo studies have reported on the pleiotropic effects of statins, such as their anti-inflammatory and anti-oxidative effects. Mechanisms of improvement of urinary ACR by statin treatment have been proposed in some reports. These reports have indicated that statins improved the urinary ACR of diabetic rats through anti-inflammatory effects and/or by the inhibition of macrophage recruitment and activation, as well as by the inhibition of TGF- $\beta$ overexpression. We suggested that oxidative stress and nitrotyrosine are related to the progression of diabetic nephropathy. Oxidative stress is defined as tissue injury induced by an increase of ROS, such as the hydroxyl radical, superoxide anion, or hydrogen peroxide. Thus, oxidative stress is considered to be one of the factors involved in the development of diabetic complications.

Isoprenoids, such as farnesyl pyrophosphate or geranylgeranyl pyrophosphate, are generated from HMG-CoA through mevalonate depletion. Isoprenoids inhibit the generation of eNOS and GTP cyclohydrolase 1 (GPTCH-1) and they also increase NAD(P)H oxidase through the inhibition of the Rho pathway and activation of Rac-1. In 2002, Chen et al. [90] reported that pravastatin, a potent inhibitor of HMG-CoA reductase, may have a direct effect as an antioxidant and suppresses the production of fibronectin (a component of the ECM) by glomerular mesangial cells independently of its hypolipidemic effect. My colleagues Gu et al. [91] suggested that pravastatin inhibits carboxymethyl lysine (CML)-induced MCP-1 expression in podocytes via modulation of key signaling cascades, including the intracellular ERK/NF- $\kappa B$ and Sp1 signaling pathways. Since pitavastatin also inhibits HMG-CoA reductase and blocks synthesis of the isoprenoids, the generation of NAD(P)H oxidase is inhibited and signals to generate eNOS are upregulated. Furthermore, statins activate GTPCH-1 and lead to the upregulation of BH4, which is essential for eNOS dimer formation. Consequently, pitavastatin activates eNOS dimerization and enforces their stability through this signaling cascade. Decrease in the monomeric form of eNOS results in a decrease in oxidative stress. 


\section{Kidney \\ Blood Pressure Research}

Kidney Blood Press Res 2014;39:450-489

\begin{tabular}{l|l}
\hline DOI: $10.1159 / 000368458$ & (C) 2014 S. Karger AG, Basel
\end{tabular}

Published onlıne: November 30, 2014

www.karger.com/kbr

472

Moreover, upregulated levels of dimeric eNOS acts as an NO generator and may work against shear stress in the early stages of diabetic nephroapthy [92]. We demonstrated that pitavastatin improves the levels of urinary ACR, urinary 8-OHdG, and ameliorates insulin resistance in KK-Ay mice independently of its cholesterol-lowering effect. Furthermore, pitavastatin prevented the accumulation of monomeric eNOS, nitrotyrosine, and p47phox in kidney tissues. It appears that pitavastatin improved not only urinary ACR but also HbA1c and impaired glucose tolerance in KK-Ay mice, possibly due to suppression of eNOS uncoupling and its antioxidant effects in diabetic nephropathy [92].

In 2010, Kimura et al. [93] examined whether pitavastatin treatment could improve renal function in CKD patients. A total of 3,119 CKD patients including some with diabetes $(1,067$ patients) were analyzed in order to evaluate the effects of pitavastatin treatment for 104 weeks on the eGFR (a sub-analysis of the LIVALO effectiveness and safety [LIVES] study). A significant increase in the eGFR $\left(+5.4 \mathrm{~mL} / \mathrm{min} / 1.73 \mathrm{~m}^{2}\right)$ was observed after 104 weeks of pitavastat in treatment $(\mathrm{p}<0.01)$. With respect to the time-course of changes in eGFR in response to pitavastatin treatment, the eGFR was elevated by $2.4 \mathrm{~mL} / \mathrm{min} / 1.73 \mathrm{~m}^{2}$ after 12 weeks' treatment, and by $5.6 \mathrm{~mL} / \mathrm{min} / 1.73 \mathrm{~m}^{2}$ after 104 weeks' treatment $(\mathrm{p}<0.001)$. The results of multivariate analysis identified the presence/absence of proteinuria and the level of change in HDL-cholesterol as clinical factors associated with increased eGFR during pitavastatin treatment. The increased eGFR was noted after 104 weeks of treatment, suggesting a possible effect of pitavastatin on CKD patients. However, an independent group, Kimura et al. [94] (Fukuoka, Japan) reported that the change in eGFR, the primary endpoint in their study, was not significantly different between the pitavastatin and pravastatin treatment groups in patients with type 2 diabetic nephropathy in the KIDNEY trial. However, the authors suggested that pitavastatin was more effective than pravastatin for the reduction of albuminuria in type 2 diabetic patients with early stages of diabetic nephropathy [94].

\section{Eicosapentaenoic acid (EPA)}

Previous studies reported that EPA was effective in the treatment of various renal diseases such as diabetic nephropathy and IgA nephropathy. EPA is one of the n-3 polyunsaturated fatty acids (PUFA) which are present in fish oil. It was shown that EPA has many effects such as anti-thrombotic, anti-hyperlipidemic, anti-atherogenic, anti-inflammatory and anti-mitogenic effects. MCP-1 is a regulatory macrophage recruitment protein, which is up-regulated in patients with diabetic nephropathy. In KK-Ay mice injected with EPA ethyl ester $(1 \mathrm{~g} / \mathrm{kg} /$ day), my colleagues Zhang et al. [95] and Hagiwara et al. [96] reported that EPA improved type 2 diabetic nephropathy by decreasing hypertriglyceridemia, glucose tolerance and albuminuria. Glomerular mesangial matrix expansion and segmental sclerosis, as well as interstitial fibrosis were markedly decreased with EPA administration. Diabetesinduced up-regulation of MCP- 1 and TGF- $\beta$ expression was inhibited by EPA, together with the reduction of glomerular macrophage infiltration and oxidative stress. It appears that EPA may be a potential therapeutic agent for diabetic nephropathy patients.

In 1995, Shimizu et al. [97] indicated that oral administration of pure eicosapentaenoic acid ethyl (EPA-E; $900 \mathrm{mg} /$ day) improved the increased urinary albumin excretion in type 2 diabetic nephropathy patients and its effects on albuminuria were sustained for at least 12 months beyond the start of treatment. However, renal tubular factors, such as beta 2-microglobulin and NAG were not influenced by EPA-E administration.

\section{$A C E$ inhibitor and $A R B$}

Angiotensin II (Ang II) exerts both hemodynamic effects, leading to increased glomerular capillary pressure, and non-hemodynamic effects such as on cell proliferation and ECM accumulation. These effects are mediated through the interaction of Ang II with its angiotensin type 1 (AT1) receptor. ACE inhibitors and ARB have been demonstrated to improve glomerular hemodynamics and structure in both human and experimental diabetic nephropathy. 


\section{Kidney Blood Pressure Research}

\begin{tabular}{l|l}
\hline Kidney Blood Press Res 2014;39:450-489 \\
\hline DOI: $10.1159 / 000368458$ & (c) 2014 S. Karger AG, Basel
\end{tabular}

Publisned oninne: November 30, 2014

www.karger.com/kbr

Tomino: Clinicopathology of Chronic Kidney Disease (CKD)

One of our studies examined the effects of candesartan (an ARB) in vivo. The results from this study demonstrated that treatment with candesartan reduced BP, ACR, accumulation of mesangial ECM components, and type IV collagen excretion without altering glucose metabolism [98]. Many studies have reported that high glucose and Ang II stimulate collagen production via TGF- $\beta$ activation. TGF- $\beta$ is an important mediator of fibrosis in the repair tissues. In our study, TGF- $\beta$ expression in glomeruli was markedly increased in the mild diabetic model of KK/Ta mice, as seen by immunohistochemistry. Candesartan administration significantly reduced TGF- $\beta$ expression. Our data also demonstrated that candesartan treatment led to an increase in the expression of glomerular Smad7, generally known as a TGF- $\beta$ signaling inhibitor [98]. It appears that the protective effects of candesartan were associated with lower glomerular hydraulic pressure, reduced TGF- $\beta$ expression, and increased Smad7 expression. It is possible that the TGF- $\beta /$ Smad signaling system plays an important role in the development and progression of diabetic nephropathy in KK/Ta mice. On the other hand, oxidative and nitrosative stresses are widely recognized as key factors in the development of diabetic nephropathy. Indeed, nitrooxidative stress and AGE production are enhanced in the kidneys of KK/Ta mice. Candesartan decreased nitrooxidative stress by down regulating $\mathrm{NAD}(\mathrm{P}) \mathrm{H}$ oxidase p37phox and iNOS expression, and modifying the interaction between AGEs and receptor of AGE (RAGE) by attenuating RAGE expression, further contributing to the reduction of AGE accumulation and subsequent albuminuria, see Fan et al. NDT, 2004, [98].

Recent evidence also indicates that adenosine monophosphate activated protein kinase (AMPK) may be a useful target for the pharmacologic treatment of type 2 diabetes. The actions of AMPK were initially defined within the context of the regulation of fatty acid and cholesterol synthesis pathways. In parallel with their activation of AMPK, anti-diabetic adipokines, i.e. adiponectin, can stimulate the phosphorylation of acetyl CoA-carboxylase, fatty acid oxidation, glucose uptake, and lactate production. We demonstrated that treatment with enalapril and/or losartan improved urinary ACR levels through activation of the adiponectin and AMPK in the kidneys of KK-Ay mice [99]. These results suggested that the renin-angiotensin system(RAS) inhibitors activated renal AMPK through its phosphorylation. Therefore, the effects of ACE inhibitors and/or ARBs, especially as combination therapy, might be associated with tissue-specific adiponectin-AMPK activity. In patients with diabetic nephropathy, combination therapy with an ACE inhibitor (lisinopril) and an ARB (losartan) decreases proteinuria but its safety profile and effects on the progression of kidney disease are still uncertain [100].

My colleagues Furukawa et al. [101] reported that the direct renin inhibitor, aliskiren, improves albuminuria and renal fibrosis by regulating inflammation and the alteration of collagen synthesis and degradation. In patients with type 2 diabetes and nephropathy, combination treatment with aliskiren plus losartan may have renoprotective effects that are independent of the blood-pressure-lowering effects [102]. Treatment with $300 \mathrm{mg}$ of aliskiren daily, as compared to placebo, reduced the mean urinary ACR by $20 \%$ (95\% confidence interval, $9-30 ; \mathrm{p}<0.001$ ), with a reduction of $50 \%$ or more in $24.7 \%$ of patients who received aliskiren as compared to $12.5 \%$ of those who received placebo $(\mathrm{p}<0.001)$ [102].

\section{Angiotensin(1-7)}

As stated previously, the generation of ROS is a major factor in the development of diabetes and its complications. NAD(P)H oxidase is an enzymatic complex that is responsible for ROS production. Ang II-mediated ROS is an important second messenger for the transcriptional effects of Ang II, and NAD(P)H oxidase is the central enzyme complex involved in Ang IIinduced ROS production. The recent discovery of the renal RAS, ACE carboxypeptidase (ACE2), and Ang-(1-7) has changed the way the RAS is viewed. Ang-(1-7) is a biologically active heptapeptide component of the RAS and is generated in the kidney at relatively high levels via enzymatic pathways that include ACE2 [103, 104]. The biological effects of Ang(1-7) in the kidneys are primarily mediated by their interaction with the G-protein-coupled receptor, Mas. My colleagues Moon et al. [105] observed that mice coinfused with Ang II 


\section{Kidney Blood Pressure Research}

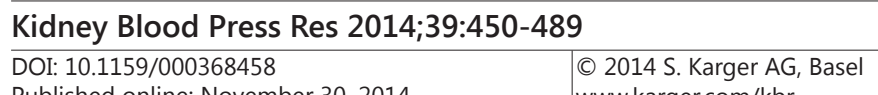

Publisned onIIne: November 30, 2014

www.karger.com/kbr

Tomino: Clinicopathology of Chronic Kidney Disease (CKD)

+ Ang-(1-7) had a lower increase in urinary ACR than mice infused with Ang II alone. In this animal model, Ang-(1-7) attenuated Ang II-mediated NAD(P)H oxidase activation and ROS production in diabetic glomeruli and mesangial cells. These findings were related to improved mesangial expansion and the production of fibronectin and TGF- $\beta 1$ in the diabetic kidneys and cultured mesangial cells. We also observed that Ang II-induced NF- $\kappa \mathrm{B}$ and MAPK activation was attenuated by Ang-(1-7) in the mesangial cells [105]. It appears that Ang-(1-7) may attenuate Ang II-stimulated NAD(P)H-dependent ROS mediated renal injury in diabetes. The ACE2-Ang-(1-7)-Mas receptor axis should be further investigated as a novel target of treatment for diabetic nephropathy.

\section{Vitamin D analogues}

The natural activator of the vitamin D receptor, calcitriol, is produced by the kidneys. However, plasma concentrations of calcitriol decline with reduced eGFR. In a multivariate analysis of CKD patients, lower calcitriol concentrations were strongly correlated with higher risk of diabetes, higher urinary ACR, and lower eGFR. Calcitriol, 1,25-dihydroxyvitamin D3 $\left(1,25(\mathrm{OH})_{2} \mathrm{D}_{3}\right)$, and its analogues have been shown to attenuate renal disease. $1,25(\mathrm{OH})_{2} \mathrm{D}_{3}$ is a negative endocrine regulator of RAS and suppresses renin biosynthesis. These data provide the molecular basis for exploring the potential of $1,25(\mathrm{OH})_{2} \mathrm{D}_{3}$ to regulate the RAS by inhibition of renin. My colleagues Ohara et al. [106] investigated the effects of therapy with $1,25(\mathrm{OH})_{2} \mathrm{D}_{3}$ on diabetic nephropathy in KK-Ay mice. Their results showed that therapy with $1,25(\mathrm{OH})_{2} \mathrm{D}_{3}$ reduced the urinary ACR levels by suppressing the compensatory renin increase in type 2 diabetic nephropathy. These beneficial effects might be related to suppression of renal expression of renin, ERK1/2, and TGF- $\beta$ which may or may not be Ang II-dependent. Moreover, a recent trial reported the anti-albuminuric effects of another analogue, paricalcitol, further strengthening the evidence that supports vitamin D analogues as renoprotective agents.

\section{Conclusions}

Diabetic nephropathy is the leading cause of ESKD worldwide. Many factors, such as genetic and non-genetic factors, hyperglycemia, the accumulation of AGEs, dyslipidemia, hyperuricemia, high protein diet, obesity, systemic and/or glomerular hypertension, and albuminuria/proteinuria itself, can influence the progression of diabetic nephropathy. However, current treatments remain suboptimal. Further research is needed to identify novel therapies for patients with diabetic nephropathy.

\section{Peritoneal Dialysis: Animal Model And Patients}

Peritoneal dialysis (PD) is an effective treatment for ESKD patients. However, long-term PD treatment is associated with a number of complications. A common functional change in the peritoneal membrane is ultrafiltration failure, which is related to the duration of PD and structural alterations in the peritoneal membrane $[107,108]$. These pathological alterations of the peritoneal membrane in long-term PD patients may progress to encapsulating peritoneal sclerosis (EPS), a serious complication in PD patients. It is well known that the characteristics of peritoneal findings in long-term PD patients are severe submesothelial compact (SMC) zone thickening, loss of mesothelial cells and neoangiogenesis with vasculopathy. Changes of peritoneal solute transport in long-term PD patients often result from an increased vascular surface area with vasculopathy. Angiogenesis and vasculopathy in the peritoneum may play an important role in the regulation of water and solute transportation in the peritoneum. However, the relationship between vascular changes and development of peritoneal fibrosis is still obscure.

Conventional PD is used Canada, the US, Europe, and Japan as a maintenance renal replacement therapy (RRT). The penetration rate of PD in Japan has only been $3-4 \%$ in recent years. Since the functional and morphological alterations of the peritoneum have been 


\section{Kidney \\ Blood Pressure Research}

\begin{tabular}{l|l}
\hline Kidney Blood Press Res 2014;39:450-489 \\
\hline DOI: $10.1159 / 000368458$ & (C) 2014 S. Karger AG, Basel
\end{tabular}

Published onlıne: November 30, 2014

www.karger.com/kbr

Tomino: Clinicopathology of Chronic Kidney Disease (CKD)

shown to increase with the duration of PD treatment, PD specialists in Japan recommend a transfer from PD to HD at around five years.

In PD patients, simple sclerosis consists of a thin layer of submesothelial sclerotic tissues. EPS in these patients is characterized by thickening sclerotic tissues involving vascular alterations. My colleagues Io and Hamada et al. [109] evaluated the serial morphologic changes and expression of angiogenic factors, i.e. vascular endothelial growth factor (VEGF), angiopoietin-1 (Ang-1), and angiopoietin-2 (Ang-2), in rat models of EPS. Twenty-four rats were given a daily intraperitoneal injection of chlorhexidine gluconate and ethanol dissolved in saline. The rats were injected with chlorhexidine gluconate and anti-VEGF neutralizing antibody simultaneously. Quantitative blood vessel evaluation was performed by staining for GS1-lectin. The mRNA expression patterns of VEGF, Ang-1, Ang-2, and their receptors were evaluated by semi-quantitative reverse transcription polymerase chain reaction (RTPCR). Immunohistochemical staining was performed in the peritoneal vessels using antiVEGF, Ang-1, and Ang-2 antisera. Hematopoietic stem cells were detected using anti-CD34 antiserum. The results showed that the blood vessel area, diameter, and length gradually increased until day 21, and then decreased. VEGF and Ang-2 mRNA expression gradually increased until day 35. In contrast, Ang-1 peaked at day 21 and then decreased significantly. Blockage of VEGF improved experimental EPS. The immunohistochemistry findings indicated that the vessels stained by VEGF and Ang- 2 were detected in the subfibrous layer. CD34-positive cells were markedly visible at day 21. Neoangiogenesis was observed in a rat model of experimental EPS. The VEGF and angiopoietin/Tie system likely plays an important role in neoangiogenesis in this animal model [109]. Further studies using this experimental rat model may help to clarify the mechanisms of EPS development in PD patients.

\section{New biomarkers of peritoneal injury in PD patients}

It is well known that peritonitis and/or the use of peritoneal dialysate that is not biocompatible may play an important role in the development of peritoneal fibrosis. In 2004, my colleagues Ro et al. [110] developed a rapid, simple, and reliable method for the diagnosis of PD peritonitis using the new MMP-9 test kit. Peritoneal inflammation continues even after the cessation of peritoneal dialysate stimulation. Therefore, it is important to establish the definition of persistent inflammation in the peritoneal cavity upon the cessation of PD. To this end, Kanda et al. [111] determined whether the levels of pentraxin 3 (PTX3) in peritoneal effluent (PE) may be a new biomarker of peritoneal injury in PD patients. Serum, PE, and peritoneal specimens were obtained from 50 patients with ESKD in our hospital. Samples from 19 patients were obtained at the initiation of $P D$ and from 31 patients at the cessation of PD. The levels of PTX3, high-sensitivity CRP, matrix metalloproteinase-2 (MMP-2) and IL-6 were analyzed. Immunohistological examinations using anti-PTX3 antiserum was also performed. Kanda et al. observed expression of PTX3 in endothelial cells, fibroblasts, and mesothelial cells in the peritoneum. The PTX3 level in PE was significantly higher at the cessation of PD compared to at initiation of PD. Effluent PTX3 levels in patients with a history of peritonitis or a PD duration of more than 8 years were significantly higher than in patients without peritonitis or patients with a PD duration of less than 8 years. The PTX3 level was significantly correlated with MMP-2 and IL-6 levels in the PE, as well as with the thickness of the SMC zone and the level of vasculopathy. These findings suggest that PTX3 may be a new biomarker of peritoneal inflammation and progressive fibrosis [111].

\section{Fundamental histological alterations in PD patients}

In 1980, Di Paolo et al. and Dobbie et al. established the International Peritoneal Biopsy Registry to gather information on the effects of PD, including peritonitis and other complications related to this therapy $[112,113]$. They also assessed the morphological findings on the peritoneal mesothelium, stroma, and blood vessels, and reported on the fundamental histological findings based on these examinations. There are three major histological peritoneal findings in PD patients: (a) a disappearance of the monolayer mesothelium, (b) thickening of the submesothelial stroma and vasculopathy, and (c) representative 


\section{Kidney Blood Pressure Research}

\begin{tabular}{l|l}
\hline Kidney Blood Press Res 2014;39:450-489 \\
\hline DOI: $10.1159 / 000368458$ & (C) 2014 S. Karger AG, Basel
\end{tabular}

Published online: November 30, 2014

www.karger.com/kbr

Tomino: Clinicopathology of Chronic Kidney Disease (CKD)

vasculopathy, including angiogenesis and stenosis, in small vessels. In 1989, Twardowski et al. [114] presented the peritoneal equilibration test (PET) as an assessment of the peritoneal membrane transport function. PET is designed to evaluate the rate of transport of small solute molecules in the peritoneum, and can be used to categorize peritoneal function in PD patients. Since then, many clinical examinations have reported the relationship between PET results and clinical findings, such as PD duration and complications. Since the 1990s, morphological assessments have focused on the relationship of PD with peritoneal function or clinical outcomes, such as ultrafiltration and peritoneal sclerosis. In 2002, Williams et al. [115] examined the relationship between morphological changes and the duration of PD using quantitative and semi-quantitative assessments. They measured the thickest section of the SMC zone as a means of assessing the development of peritoneal fibrosis. Later, we proposed that the average thickness of the SMC zone provides a more objective assessment of peritoneal fibrosis, as the average peritoneal thickness increases with the duration of PD. Williams et al. [115] also presented a semi-quantitative assessment of vasculopathy in PD patients. They classified the severity of vasculopathy into four grades: normal, hyalinized vascular wall thickening, luminal narrowing, and obstruction. A uremic condition introduces vascular morphological changes. In patients with ultrafiltration failure, vasculopathy findings were more severe than in other patients.

In 2008, Honda et al. [116] reported that vascular patency showed a good relationship with PD duration. In the analysis, they selected the predominant vascular findings in several post-capillary venules between $25-50 \mu \mathrm{m}$ in diameter, and then measured the distances in the short axis. The patency was shown as the rate of luminal diameter per vascular diameter. The authors found that the patency was related to peritoneal functional changes. This assessment is available to every physician for evaluating vasculopathy. In our previous study [117], PD patients with low vascular patency of membrane indicated a high transport. Angiogenesis is one of the characteristic vascular findings in PD patients. The number of vessels was significantly increased five years after PD initiation. Although an increase in the number of blood vessels in the stroma was observed in PD patients, there was no significant relationship between the number of vessels and PD duration [107]. It is thought that the vascular number could be indicative of serious peritoneal damage, such as membrane failure and peritoneal sclerosis.

\section{Qualitative alterations in the peritoneal interstitium}

We have clinical experience with patients with EPS, a rare but serious complication of PD. The clinical characteristics have been thoroughly determined in order to clarify the risks of EPS and to establish preventative methods. In our experience, the prevalence of EPS increases with the duration of PD. Based on this background, peritoneal morphologic findings have been used to assess the differences between peritoneal fibrosis and sclerosis in order to establish the characteristics of peritoneal sclerosis. In the 1990s, Hirano et al. established the Japanese Peritoneal Biopsy Registry, supported by Baxter Corporation (Baxter Japan, Tokyo, Japan). After assessing a large number of Japanese peritoneal specimens, Hirano et al. outlined the morphological differences between peritoneal fibrosis and sclerosis. In particular, they examined the qualitative changes in the thickened subepithelial stroma. An important observation was the accumulation of laminin-rich type III collagen in peritoneal sclerosis patients (unpublished data).

Yokoyama et al. [118] reported that serum levels of $\beta 2$-microglobulin $(\beta 2-\mathrm{MG})$ is a potential predictor for EPS. Not surprisingly, they demonstrated the accumulation of $\beta 2$-MG in the peritoneal stroma. Therefore, not only peritoneal thickening but also constitutive ECM changes may occur in peritoneal sclerosis. The accumulation of $\beta 2-\mathrm{MG}$ in the peritoneum was examined by my colleagues Nakamoto et al. [119]. $\beta 2-\mathrm{MG}$ deposition was not observed in non-CKD patients. In long-term PD patients, the expression of $\beta 2-M G$ was evident in the perivascular areas and extended to the whole peritoneum. The $\beta 2-\mathrm{MG}$ expression area in the peritoneum of long-term PD patients was significantly higher than that in uremic and short-term PD patients. In our study, a portion of the $\beta 2-\mathrm{MG}$ positive region overlapped with 

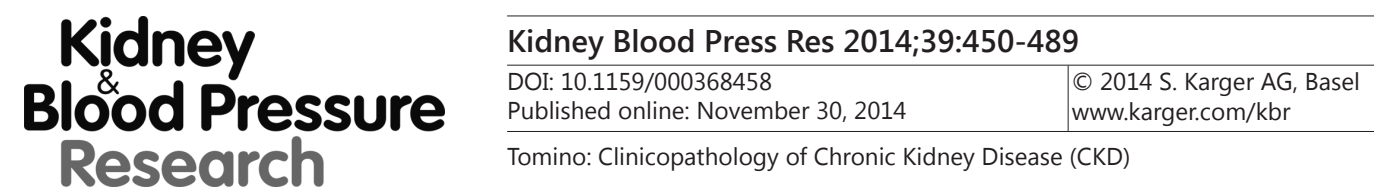

Published onIIne: November 30, 2014

www.karger.com/kbr

the AGE-expressing regions. Therefore, thickening of the peritoneum is not only caused by collagen deposition but may also be a result of the accumulation of degenerated $\beta 2$-MG. We also examined the changes in the ECM, with special emphasis on proteoglycans in the peritoneum [120]. Decorin belongs to the small proteoglycan family and is able to inhibit the activity of TGF- $\beta 1$. In the fibrotic-thickened peritoneum of long-term PD patients, decorin levels were markedly decreased regardless of the presence of peritonitis. Versican is a large ECM proteoglycan and is a key factor in the inflammation process. Notably, versican was not detected in the normal peritoneum but was detected in the long-term PD peritoneum, and was especially intense in patients with peritonitis [120].

Peritoneal calcification is one of the key radiographic findings in EPS patients. In 2002, Nakazato et al. [121] demonstrated that microscopic peritoneal calcification is frequently observed in patients who have undergone PD for more than 10 years. Furthermore, myofibroblast infiltration and osteopontin expression were observed in the areas of massive calcium deposits. However, the areas of osteopontin expression did not coincide with scattered granular or crystalloid calcifications. The authors suggested that the presence of degenerated ECM, AGEs, and fibrin might increase the affinity for hydroxyapatite. Podoplanin is a marker of endothelial cells, especially lymphatic endothelial cells. The expression of podoplanin mRNA was increased in EPS patients; furthermore, podoplanin expression was observed in the peritoneum in EPS patients [122]. This suggests that lymphangiogenesis may be a morphological characteristic of EPS.

\section{Effect of biocompatible peritoneal solution in histological alterations}

My colleagues Hamada et al. [107] have been trying to determine the relationship between morphological changes and clinical outcomes, for example, the relationship between peritoneal functional changes and prognosis after withdrawal of PD. We have used several strategies such as a neutral PD solution, hybrid PD (PD+HD) therapy, peritoneal lavage and drugs to prevent peritoneal damage. However, there have been few clinical studies focusing on morphological assessment. The Japanese Society for Peritoneal Dialysis (JSPD) established the Peritoneal Biopsy Study Group several years ago and examined the benefits of a neutral PD solution on histological changes in the peritoneum. Although the use of a neutral PD solution had no effects on peritoneal thickening, the neutral PD solution significantly suppressed the development of vasculopathy compared with the use of an acidic PD fluid (manuscript submitted).

Inhibitory effects of the matrix metalloproteinase inhibitor ONO-4817 on morphological alterations in chlorhexidine gluconate ( $\mathrm{CH}$ )-induced peritoneal sclerosis rats

The activity of gelatinase, or matrix metalloproteinase (MMP)-2, in the effluent was increased in PD patients with EPS and in chlorhexidine gluconate $(\mathrm{CH})$-induced peritoneal sclerosing animal models. Ro et al. [123] investigated the effect of an MMP inhibitor (ONO4817, Ono Pharmaceutical Co.,Osaka, Japan), an anticancer agent with anti-angiogenic and anti-infiltration effects, on the development of peritoneal fibrosis in $\mathrm{CH}$-induced peritoneal sclerosis rats. Forty-five Sprague-Dawley rats were intraperitoneally injected with saline as control or with $\mathrm{CH}(1.5 \mathrm{~mL} / 100 \mathrm{~g})$. ONO-4817 (5 mg/rat) was administered intravenously to the $\mathrm{CH}$ rats (the ONO-4817 group) from initiation to the end of the study. After 22 days of ONO-4817 administration, the rats were sacrificed and the parietal peritoneum was harvested. The gene expressions of TGF- $\beta, \alpha$-smooth muscle actin ( $\alpha$-SMA) and type I collagen in the peritoneum were analysed by RT-PCR. Peritoneal tissues were also evaluated immunohistologically. ONO-4817 significantly inhibited the thickening of the submesothelial layer and the accumulation of type I collagen in the peritoneum. Treatment with ONO-4817 also prevented increases in the number of macrophages and blood vessels. The expressions of TGF- $\beta, \alpha$-SMA and type I collagen in the peritoneum were markedly suppressed in ONO4817-treated rats. It appears that the administration of the MMP inhibitor ONO-4817 may be a new approach for the amelioration of peritoneal sclerosis [123]. 


\section{Kidney Blood Pressure Research}

Cardiac structure and function in longitudinal analyses of echocardiography in PD patients

Echocardiography is widely used for the evaluation of cardiac structure and function [124]. The prognostic value of assessment of the left cardiac atrium (LA) size in PD patients is still unclear. Along with my colleagues, Io et al. [125], we prospectively examined a longitudinal monitoring of echocardiography parameters after the start of PD. We also prospectively investigated the correlation between plasma atrial natriuretic peptide (ANP) levels, LA size, and cardiac function by Doppler echocardiography in 32 patients undergoing PD in our hospital. Measurement of these parameters was performed 0, 6, 12, 18, and 24 months after initiation of PD. All patients were treated with an ARB to maintain $\mathrm{BP}$ to less than $140 / 90 \mathrm{mmHg}$. Other anti-hypertensive drugs such as diuretics and/ or CCBs were added if BP increased beyond 140/90 mmHg. Hemoglobin and hematocrit levels were targeted at $10.0 \mathrm{~g} / \mathrm{dL}$ and $30.0 \%$, respectively, using recombinant human erythropoietin treatment. A diuretic was added, or patients decreased their water intake if plasma ANP was more than $43.0 \mathrm{pg} / \mathrm{mL}$, LA diameter more than $39 \mathrm{~mm}$, or according to other basic markers of volume status. Cardiac function was measured before and after drainage of PD fluid to evaluate the influence of cardiac function. LA diameter at initiation of dialysis $(36 \pm 4.6 \mathrm{~mm})$ significantly decreased to $33 \pm 3.3 \mathrm{~mm}(\mathrm{p}<0.05), 33 \pm 3.2 \mathrm{~mm}$ $(\mathrm{p}<0.05)$, and $33 \pm 3.6 \mathrm{~mm}(\mathrm{p}<0.05)$ after 6,12 , and 24 months, respectively. Ejection fraction after 6 months was significantly increased compared to at the initiation of PD $(\mathrm{p}<0.05)$. Left ventricular mass index (LVMI) after 6, 12, and 24 months was significantly decreased compared to at the initiation of PD ( $<<0.05)$. Plasma ANP was $56 \pm 39 \mathrm{pg} / \mathrm{mL}$ at initiation of PD and decreased significantly to $33 \pm 19 \mathrm{pg} / \mathrm{mL}$ after 24 months $(\mathrm{p}<0.05)$. The plasma ANP level was significantly correlated with LA diameter, transmitral A wave flow velocity, and LVMI ( $p<0.01$, respectively). Instillation of the PD fluid did not affect any parameters except inferior vena cava dimension. The results from this clinical study demonstrated a reduction in LA size and LVMI in PD patients who were followed over 24 months. Left ventricular structure, contraction, and compliance were well preserved in PD patients undergoing PD based on measurements of plasma ANP and LA diameter [125].

\section{Conclusions}

Morphologic changes in the peritoneum, such as peritoneal fibrosis and vasculopathy, develop during PD. A random-points measurement of the average SMC zone thickness provides a qualitative means of evaluating the severity of peritoneal fibrosis while minimizing artifacts and human error during processing. The echocardiography technique is widely used for the evaluation of cardiac structure and function in PD patients.

\section{Hemodialysis (HD): symptoms, progression and prevention}

Complement system. Hemodialysis (HD) patients are well known as compromised hosts. The major causes of death in HD patients worldwide are infections, carcinomas, and cardiovascular diseases. The complement system plays a central role in innate immunity and is known to be involved in the pathogenesis of inflammatory diseases and the mechanisms of host defense. The complement system is activated via three pathways: 1) the classical pathway, 2) the alternative pathway, and 3) the lectin pathway, see Ishii et al. [126]. Mannosebinding lectin (MBL) and L-ficolin are the initiating molecules of the lectin pathway and recognize pathogen-associated molecular patterns such as carbohydrates expressed on the surfaces of microbes. Activation of the lectin pathway is followed by cleavage of $\mathrm{C} 4$ and C2 by MBL-associated serine protease-2 (MASP-2), which forms complexes with MBL and L-ficolin in plasma. Thereafter, the complement cascades proceed to form membrane attack complexes.

The plasma concentration of MBL varies in humans within three orders of magnitude [127]. This variation is determined by three single nucleotide polymorphisms (SNPs) within exon 1 of the $M b l-2$ gene and several promoter regions of the $M B L$ gene [128]. The presence of mutations results in a failure to form a fully functional multimeric protein. MBL deficiency is observed in almost $5-10 \%$ of healthy people, but the clinical significance of MBL deficiency 


\section{Kidney Blood Pressure Research}

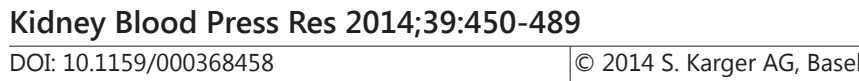

Published onlıne: November 30, 2014

www.karger.com/kbr

Tomino: Clinicopathology of Chronic Kidney Disease (CKD)

is controversial [129]. Several studies have shown that MBL deficiency increases the overall susceptibility to infectious diseases. On the other hand, most people with MBL deficiency apparently lead healthy lives without increased rates of infectious diseases or increased mortality [130]. In maintenance HD patients, the distribution of the serum concentrations of MBL has rarely been reported. Thus, it is still unknown whether MBL deficiency is a risk factor for HD induction in ESKD patients.

L-ficolin is a serum lectin and recognizes $\mathrm{N}$-acetylglucosamine, but not mannose, as a ligand. A few recent studies have revealed that a low concentration of L-ficolin correlated with recurrent respiratory infections in childhood [131], but there is no data regarding the serum concentrations of L-ficolin in maintenance HD patients. In collaboration with Inoshita et al. [132], we performed a study on complement deficiencies screened by measurement of functional activities of the three complement pathways in HD patients. We focused on serum MBL levels to observe if MBL deficiency was a risk factor for life-threatening infections in HD patients. Our study revealed that there was no functional risk of mortality or major infection. It appears that although complement deficiencies exist among HD patients and healthy controls, the complement deficiencies do not confer an increased risk of mortality in HD patients [132].

MBL, L-ficolin, and MASP-2 are molecules involved in the initiation of the lectin pathway in the complement system. Although MBL deficiency is observed in almost $10 \%$ of healthy people, studies on the association between MBL deficiency and ESKD remain rare. Along with my colleagues Ishii et al. [126], we clarified the significance of the lectin pathway in maintenance HD patients, especially in terms of MBL levels. Two hundred and forty-four HD patients who had been followed up and 199 healthy controls were included in our study. Measurements of serum concentrations of MBL, L-ficolin, and MASP-2 were performed. Low serum MBL levels (less than $0.1 \mathrm{mg} / \mathrm{mL}$ ) in the patients were confirmed by examination of a point mutation in the $\mathrm{Mbl}-2$ gene. Seventeen HD patients (7\%) and 20 healthy controls $(10 \%)$ had MBL deficiency. During the follow-up period, 99 patients died. There was no significant difference in the frequency of deaths from infectious diseases between MBL deficient patients and patients who did not have MBL deficiency. In both HD patients and healthy controls with MBL deficiency, the serum concentrations of L-ficolin tended to be high, and that of MASP-2 was significantly higher ( $p<0.05)$. Overall, our results indicated that MBL deficiency is not a risk factor for HD induction or life-threatening infections. It is possible that the elevate concentrations of these two key components in the lectin pathway (L-ficolin and MASP-2) may compensate for the insufficient activity of the lectin pathway in MBL deficiency [126].

\section{Pruritus in hemodialysis patients}

Although pruritus is a common complication in maintenance HD patients, the pathophysiological mechanisms remain obscure. B-type (brain) natriuretic peptide (BNP) has been defined as an itch-selective neuropeptide in pruriceptive neurons in mice, and higher serum levels of BNP are frequently observed in HD patients. My colleagues Shimizu et al. [133] evaluated the role of serum BNP in pruritus in HD patients. A cross-sectional study was performed on 43 patients undergoing maintenance HD. A visual analog scale (VAS) measuring the general severity of pruritus (values from 0 to 10 with higher values indicating more severe pruritus) in the daytime and nighttime was self-reported by patients. Each patient's background and laboratory tests, including serum BNP levels in the post-HD period, were collected. The correlation between VAS values and clinical parameters was evaluated. The results showed that both daytime and nighttime VAS values in diabetic HD patients were significantly less than those in non-diabetic HD patients. Multiple regression analysis revealed that pruritus in the daytime was worsened by serum BNP and $\beta_{2}$-MG levels, whereas it was eased by age. Nocturnal pruritus was severe in non-diabetic patients and was weakened by the total iron binding capacity [133]. 


\section{Kidney Blood Pressure Research}

Left ventricar hypertrophy

Left ventricular (LV) hypertrophy and dysfunction is the most powerful indicator of mortality and cardiovascular complications in CKD patients. We have examined cardiovascular function in CKD patients using ultrasonography [124, 125, 134, 135]. Nakatani et al. [136] showed that the plasma ANP level is one of the most important risk predictors of LV hypertrophy. The correlation between plasma ANP and LV mass was observed previously $[124,125,134,135]$. It has been hypothesized that left atrium (LA) size represents the integration of LV diastolic performance (compliance) over time. Thus, LA volume provides a long term view of diastolic dysfunction, regardless of the loading conditions and filling pressure present at the time of examination [137]. Studies on HD patients without hypertension suggest that LV hypertrophy may be related to factors such as hyperparathyroidism, sympathetic activity, reflection of the pulse wave due to stiffened arteries and anemia. A previous study reported that normalization of hemoglobin levels (13-14 g/dL) with erythropoietin treatment did not induce regression of LV dilatation or concentric LV hypertrophy [138]. On the other hand, another study showed that treatment of renal anemia with erythropoietin improved cardiac performance and induced regression of LV hypertrophy [139]. In our study, the mean $\mathrm{Hb}$ level was significantly improved after initiation of HD, and this was maintained during the observation period. The LVMI tended to decrease after 24 months in our study [134]. Comparable BP control between the groups may have mitigated the potential development of LV hypertrophy. In contrast, in patients who did achieve the protocol BP targets, changes in LVMI were consistent with findings from previous studies that identified anemia as an independent predictor of LV hypertrophy [140], with changes in volume-based parameters that might be of particular importance as determinants of LV growth. Therefore, there is some evidence that avoidance of anemia, together with control of BP and volume status, might favorably affect LV growth among HD patients. Another study reported that normotensive HD patients showed no decrease in LV hypertrophy for 2.5 years although the LA diameter increased [141]. Failure to correct the hidden volume expansion may at least partially explain the persistence or development of LVH. This finding is supported by studies on daily HD [142], a treatment modality that greatly facilitates volume control. In patients on nocturnal HD, there is a notable reduction in the LVMI and in LV function [143]. Total peripheral vascular resistance is decreased with endothelium-dependent vasodilatation restored [144]. Some, but not all studies, have demonstrated a decrease in erythropoietin requirements among patients converting from thrice-weekly HD to nocturnal HD. Thus, my colleagues Io et al. [134] suggested several recommendations along with a possible algorithm for reducing LVH in HD patients. BP must be kept lower and serum albumin must be maintained, for example, by decreasing urinary protein before initiation of HD. Systolic BP must be kept lower and plasma ANP must be decreased by controlling overhydration, and $\mathrm{Hb}$ levels must be maintained after initiation of HD. Attention should be paid to activation of the RAAS, in particular increased angiotensin II levels, and stimulated growth of myocardial cells [145]. Increased plasma angiotensin II levels have been linked to left LV mass independently of BP.

ARBs are the most effective drugs for reducing LV mass in patients with essential hypertension. Treatment with ARB may be associated with a reduction in the LVMI to some extent. Therefore, in our study, all patients were treated with ARB to control BP, though the lack of a control group and randomization was a limitation of the study [134]. The residual GFR (rGFR) may have an important impact on the ability to deliver adequate fluid balance. However, once rGFR is too low or absent, the control of fluid balance as well as hypertension becomes more difficult. There were some patients who were treated with increased doses of CCB and ARB. All patients needed to lose BW for regulating dry weight. Therefore, maintaining the fluid balance may be an important approach for reducing the risk of death in HD patients. Indeed, our results showed that the rGFR was decreased for 6 months after initiation of HD, and control of BP is difficult during follow-up. The significant change in BP may have led to the reduction of LV hypertrophy. Thus, the changes of LVMI may have occurred via a reduction in $\mathrm{LV}$ end diastolic pressure, leading to a reduction in LA diameter. 


\section{Kidney Blood Pressure Research}

Kidney Blood Press Res 2014;39:450-489

\begin{tabular}{l|l}
\hline DOI: 10.1159/000368458 & (c) 2014 S. Karger AG, Basel
\end{tabular}

Published onine: November 30, 2014

www.karger.com/kbr

481

\section{Conclusions}

The frequency of MBL deficiency appears to be almost the same in HD patients and in healthy controls. MBL deficiency is not a risk factor for induction of HD in patients with ESKD. The cause of death in HD patients also had no relation to MBL deficiency. It is thought that up-regulation of key components of the lectin pathway, namely L-ficolin and MASP-2, may compensate in lectin pathway activation in MBL deficiency. Higher serum levels of BNP may increase the degree of pruritus in HD patients in the daytime, however, diabetic HD patients are less sensitive to itch especially in the nighttime.

It appears that BP, rGFR and serum albumin levels are predictive factors for LVMI at the initiation of HD. Systolic blood pressure (BP), plasma ANP and hemoglobin levels were predictive factors for LVMI after initiation of HD. It is important to treat hypertension before initiation of HD, and to treat hypertension, overhydration based on plasma ANP and anemia after that of HD. These findings have therapeutic implications for the treatment strategy used for pre-dialysis and HD patients.

\section{Abbreviations}

$\mathrm{ACE}=$ angiotensin-converting enzyme; $\mathrm{ACR}=$ albumin to creatinine ratio; $\mathrm{AGE}=$ advanced glycation end products; $\mathrm{AMPK}=$ adenosine monophosphate activated protein kinase; AngII = angiotensin II; ANP = atrial natriuretic peptide; $\mathrm{AOE}=$ antioxidant enzyme; Apo = apolipoprotein; ARB = angiotensin-receptor blocker; AT1 = angiotensin type I; $\beta 2$ $\mathrm{MG}=\beta 2$-microglobulin; $\mathrm{BMC}$ = bone marrow-derived cells; $\mathrm{BMT}=$ bone marrow transplant; $\mathrm{BNP}=$ brain natriuretic peptide; $\mathrm{BP}=$ blood pressure; $\mathrm{BW}=$ body weight; $\mathrm{C} 3$ = complement 3; $\mathrm{CH}=$ chlorhexidine gluconate; $\mathrm{CH} 50=50 \%$ hemolytic unit of complement; $\mathrm{CKD}=$ chronic kidney disease; $\mathrm{CCB}=$ calcium channel blocker; $\mathrm{Ccr}=$ creatinine clearance; $\mathrm{CML}$ $=\mathrm{N}(\varepsilon)$-carboxymethl-lysine; $\mathrm{CRP}=$ complement regulatory protein; $\mathrm{CT}=$ computerized tomography; DDS = drug delivery systems; ECM = extracellular matrix; EDD = electrondense deposits; GFR =glomerular filtration rate, eGFR = estimated glomerular filtration rate; $\mathrm{rGFR}=$ residual glomerular filtration rate; EPS = encapsulating peritoneal sclerosis; ESKD = end-stage kidney disease; EPA = eicosapentaenoic acid; ex-C3 = extraglomerular C3; GBM = glomerular basement membrane; Gd-IgA1 = galactose-deficient IgA1; GPTCH-1 = guanosine triphosphate cyclohydrolase $(\mathrm{GTPCH})-1 ; \mathrm{HG}=$ histological grade; $\mathrm{HIGA}=$ high serum IgA ddY; HMG-CoA = 3-hydroxy-3-methylglutaryl-coenzyme A; ICAM-1 = intercellular adhesion molecule-1; IFN = interferon; IL = interleukin; JDS = Japan Diabetes Society; JSDT = Japanese Society of Dialysis Therapy; JSN = Japanese Society of Nephropathy; LA = left cardiac atrium; $L A D=L A$ diameter; $L D L=$ low density lipoprotein; $L V=$ left ventricular; $m A b$ = monoclonal antibody; LVMI = left ventricular mass index; MASP-2 = MBL-associated serine protease-2; MBL = Mannose-binding lectin; $\mathrm{MCP}-1$ = monocyte chemoattractant protein-1; MCT = mast cells containing only tryptase; $\mathrm{MCTC}=$ mast cells containing both tryptase and chymase; MG = microglobulin; MyD88 = Myeloid differentiation factor 88; NAG = N-acetylbeta-D glucosaminidase; NOS = nitric oxide synthase; PAN = puromycin aminonucleoside; PAS = periodic acid-Schiff; $\mathrm{PCR}=$ protein to creatinine ratio; $\mathrm{PD}=$ peritoneal dialysis; $\mathrm{PDGF}$ $=$ platelet-derived growth factor; $\mathrm{PE}=$ peritoneal effluent; $\mathrm{PET}=$ peritoneal equilibration test; PSL = prednisolone; PTX3 = pentraxin 3; RAS =renin angiotensin system; RAAS = renin angiotensin aldosterone system; $\mathrm{RBC}=$ red blood cell; $\mathrm{RBF}=$ renal blood flow; ROS = reactive oxygen species; RRT $=$ renal replacement therapy; RT-PCR = reverse transcription polymerase chain reaction; SBP = systolic blood pressure; $\mathrm{SC}=$ secretory component; SHR = spontaneous hypertensive rats; SIgA = secretory IgA; SMA = smooth muscle actin; SMC = submesothelial compact; SNP = single nucleotide polymorphisms; STZ = streptozotocin; TC = total cholesterol; TLR $=$ toll-like receptor; $\mathrm{TG}=$ triglyceride; $\mathrm{TNF}=$ tumor necrosis factor; TNFR = TNF receptor; VAS = visual analog scale; VEGF = vascular endothelial growth factor. 


\section{Kidney \\ Blood Pressure Research}

\section{Kidney Blood Press Res 2014;39:450-489}

\begin{tabular}{l|l}
\hline DOI: $10.1159 / 000368458$ & (C) 2014 S. Karger AG, Basel
\end{tabular}

Publisned ontIne: November 30, 2014

www.karger.com/kbr

\section{Acknowledgements}

I wish to thank my colleagues, especially the basic and clinical research group leaders, for supporting me throughout the years in the Division of Nephrology, Department of Internal Medicine, Juntendo University Faculty of Medicine, Tokyo, Japan.

The current leaders of the basic and clinical research groups in my division are:

- $\quad$ IgA nephropathy: Dr. Yusuke Suzuki

- Diabetic nephropathy: Dr. Tomohito Gohda

- $\quad$ Peritoneal dialysis: Dr. Chieko Hamada

- Hemodialysis: Dr. Yoshio Shimizu

- Ultrasonography: Dr. Hiroaki Io

- $\quad$ Complement : Dr. Isao Ohsawa

- $\quad$ Podocyte biology: Dr. Teruo Hidaka

- Biomarker: Dr. Satoshi Horikoshi

\section{References}

Berger J, Hinglais N: Intercapillary deposits of IgA-IgG. J Urol Nephrol (Paris) 1968;74:694-695.

Nakayama K, Ohsawa I, Maeda-Ohtani A, Murakoshi M, Horikoshi S, Tomino Y: Prediction of diagnosis of immunoglobulin A nephropathy prior to renal biopsy and correlation with urinary sediment findings and prognostic grading. J Clin Lab Anal 2008;22:114-118.

-3 Working Group of the International Ig ANN, the Renal Pathology S, Cattran DC, Coppo R, Cook HT, Feehally J, Roberts IS, Troyanov S, Alpers CE, Amore A, Barratt J, Berthoux F, Bonsib S, Bruijn JA, D'Agati V, D'Amico G, Emancipator S, Emma F, Ferrario F, Fervenza FC, Florquin S, Fogo A, Geddes CC, Groene HJ, Haas M, Herzenberg AM, Hill PA, Hogg RJ, Hsu SI, Jennette JC, Joh K, Julian BA, Kawamura T, Lai FM, Leung CB, Li LS, Li PK, Liu ZH, Mackinnon B, Mezzano S, Schena FP, Tomino Y, Walker PD, Wang H, Weening JJ, Yoshikawa $\mathrm{N}$, Zhang H: The Oxford classification of IgA nephropathy: rationale, clinicopathological correlations, and classification. Kidney Int 2009;76:534-545.

- Kawamura T, Joh K, Okonogi H, Koike K, Utsunomiya Y, Miyazaki Y, Matsushima M, Yoshimura M, Horikoshi S, Suzuki Y, Furusu A, Yasuda T, Shirai S, Shibata T, Endoh M, Hattori M, Katafuchi R, Hashiguchi A, Kimura K, Matsuo S, Tomino Y, Study Group Special Ig AN: A histologic classification of IgA nephropathy for predicting long-term prognosis: emphasis on end-stage renal disease. J Nephrol 2013;26:350-357.

-5 Roos A, Rastaldi MP, Calvaresi N, Oortwijn BD, Schlagwein N, van Gijlswijk-Janssen DJ, Stahl GL, Matsushita M, Fujita T, van Kooten C, Daha MR: Glomerular activation of the lectin pathway of complement in IgA nephropathy is associated with more severe renal disease. J Am Soc Nephrol 2006;17:1724-1734.

6 Onda K, Ohi H, Tamano M, Ohsawa I, Wakabayashi M, Horikoshi S, Fujita T, Tomino Y: Hypercomplementemia in adult patients with IgA nephropathy. J Clin Lab Anal 2007;21:77-84.

-7 Suzuki H, Ohsawa I, Kodama F, Nakayama K, Ohtani A, Onda K, Nagamachi S, Kurusu A, Suzuki Y, Ohi H, Horikoshi S, Tomino Y: Fluctuation of serum C3 levels reflects disease activity and metabolic background in patients with IgA nephropathy. J Nephrol 2013;26:708-715.

-8 Shimamoto M, Ohsawa I, Suzuki H, Hisada A, Nagamachi S, Honda D, Inoshita H, Shimizu Y, Horikoshi S, Tomino Y: Impact of body mass index on progression of IgA nephropathy among Japanese patients. J Clin Lab Anal 2014, DOI 10.1002/jcla.21778.

-9 Ohsawa I, Kusaba G, Ishii M, Sato N, Inoshita H, Onda K, Hashimoto A, Nagamachi S, Suzuki H, Shimamoto M, Ohi H, Horikoshi S, Tomino Y: Extraglomerular C3 deposition and metabolic impacts in patients with IgA nephropathy. Nephrol Dial Transplant 2013;28:1856-1864.

10 Kusaba G, Ohsawa I, Ishii M, Inoshita H, Takagi M, Tanifuji C, Takahashi K, Nakamoto J, Yoshida M, Ohi H, Horikoshi S, Kurihara H, Tomino Y: Significance of broad distribution of electron-dense deposits in patients with IgA nephropathy. Med Mol Morphol 2012;45:29-34.

11 Lemley KV, Lafayette RA, Safai M, Derby G, Blouch K, Squarer A, Myers BD: Podocytopenia and disease severity in IgA nephropathy. Kidney Int 2002;61:1475-1485. 


\section{Kidney \\ Blood Pressure Research}

Kidney Blood Press Res 2014;39:450-489

\begin{tabular}{l|l}
\hline DOI: $10.1159 / 000368458$ & (C) 2014 S. Karger AG, Basel
\end{tabular}

Publisned ontıne: November 30, 2014

www.karger.com/kbr

12 Hishiki T, Shirato I, Takahashi Y, Funabiki K, Horikoshi S, Tomino Y: Podocyte injury predicts prognosis in patients with IgA nephropathy using a small amount of renal biopsy tissue. Kidney Blood Press Res 2001;24:99-104.

13 Kodama F, Asanuma K, Takagi M, Hidaka T, Asanuma E, Fukuda H, Seki T, Takeda Y, Hosoe-Nagai Y, Asao R, Horikoshi S, Tomino Y: Translocation of dendrin to the podocyte nucleus in acute glomerular injury in patients with IgA nephropathy. Nephrol Dial Transplant 2013;28:1762-1772.

14 Sakamoto-Ihara T, Suzuki Y, Kurusu A, Yamashita M, Horikoshi S, Tomino Y: Possible involvement of mast cells in renal fibrosis in patients with IgA nephropathy. Inflamm Res 2007;56:421-427.

-15 Imai H, Nakamoto Y, Asakura K, Miki K, Yasuda T, Miura AB: Spontaneous glomerular IgA deposition in ddY mice: an animal model of IgA nephritis. Kidney Int 1985;27:756-761.

16 Suzuki H, Suzuki Y, Yamanaka T, Hirose S, Nishimura H, Toei J, Horikoshi S, Tomino Y: Genome-wide scan in a novel IgA nephropathy model identifies a susceptibility locus on murine chromosome 10, in a region syntenic to human IGAN1 on chromosome 6q22-23. J Am Soc Nephrol 2005;16:1289-1299.

17 Gharavi AG, Yan Y, Scolari F, Schena FP, Frasca GM, Ghiggeri GM, Cooper K, Amoroso A, Viola BF, Battini G, Caridi G, Canova C, Farhi A, Subramanian V, Nelson-Williams C, Woodford S, Julian BA, Wyatt RJ, Lifton RP: IgA nephropathy, the most common cause of glomerulonephritis, is linked to 6q22-23. Nat Genet 2000;26:354-357.

18 Liao J, Hayashi K, Horikoshi S, Ushijima H, Kimura J, Tomino Y: Effect of steroid-liposome on immunohistopathology of IgA nephropathy in ddY mice. Nephron 2001;89:194-200.

19 Shimizu M, Shou I, Tsuge T, Abe M, Tomino Y: Effect of mizoribine on glomerulonephritis of early-stage IgA nephropathy in ddY mice. Nephron 1998;79:67-72.

20 Tomino Y, Shimizu M, Koide H, Abe M, Shirai T: Effect of monoclonal antibody CD4 on glomerulonephritis of ddY mice, a spontaneous animal model of IgA nephropathy. Am J Kidney Dis 1993;21:427-432.

21 Sakai O: IgA nephropathy: current concepts and future trends. Nephrology 1997;3:2-3.

22 Imasawa T, Nagasawa R, Utsunomiya Y, Kawamura T, Zhong Y, Makita N, Muso E, Miyawaki S, Maruyama N, Hosoya T, Sakai O, Ohno T: Bone marrow transplantation attenuates murine IgA nephropathy: role of a stem cell disorder. Kidney Int 1999;56:1809-1817.

23 Suzuki H, Suzuki Y, Aizawa M, Yamanaka T, Kihara M, Pang H, Horikoshi S, Tomino Y: Th1 polarization in murine IgA nephropathy directed by bone marrow-derived cells. Kidney Int 2007;72:319-327.

24 Bonner A, Furtado PB, Almogren A, Kerr MA, Perkins SJ: Implications of the near-planar solution structure of human myeloma dimeric IgA1 for mucosal immunity and IgA nephropathy. J Immunol 2008;180:10081018.

25 Kokubo T, Hiki Y, Iwase H, Tanaka A, Toma K, Hotta K, Kobayashi Y: Protective role of IgA1 glycans against IgA1 self-aggregation and adhesion to extracellular matrix proteins. J Am Soc Nephrol 1998;9:2048-2054.

-26 Yan Y, Xu LX, Zhang JJ, Zhang Y, Zhao MH: Self-aggregated deglycosylated IgA1 with or without IgG were associated with the development of IgA nephropathy. Clin Exp Immunol 2006;144:17-24.

-27 Oortwijn BD, van der Boog PJ, Roos A, van der Geest RN, de Fijter JW, Daha MR, van Kooten C: A pathogenic role for secretory IgA in IgA nephropathy. Kidney Int 2006;69:1131-1138.

-28 Suzuki H, Suzuki Y, Narita I, Aizawa M, Kihara M, Yamanaka T, Kanou T, Tsukaguchi H, Novak J, Horikoshi S, Tomino Y: Toll-like receptor 9 affects severity of IgA nephropathy. J Am Soc Nephrol 2008;19:2384-2395.

29 Tomino Y, Ohmuro H, Kuramoto T, Shirato I, Eguchi K, Sakai H, Okumura K, Koide H: Expression of intercellular adhesion molecule-1 and infiltration of lymphocytes in glomeruli of patients with IgA nephropathy. Nephron 1994;67:302-307.

-30 Maeda A, Gohda T, Funabiki K, Horikoshi S, Shirato I, Tomino Y: Significance of serum IgA levels and serum IgA/C3 ratio in diagnostic analysis of patients with IgA nephropathy. J Clin Lab Anal 2003;17:73-76.

-31 Saitoh A, Suzuki Y, Takeda M, Kubota K, Itoh K, Tomino Y: Urinary levels of monocyte chemoattractant protein (MCP)-1 and disease activity in patients with IgA nephropathy. J Clin Lab Anal 1998;12:1-5.

-32 Tomino Y, Funabiki K, Ohmuro H, Shimizu M, Yokoyama K, Shirato I, Shirai T, Takahashi M, Koide H: Urinary levels of interleukin- 6 and disease activity in patients with IgA nephropathy. Am J Nephrol 1991;11:459464.

33 Yanagawa H, Suzuki H, Suzuki Y, Kiryluk K, Gharavi AG, Matsuoka K, Makita Y, Julian BA, Novak J, Tomino Y: A panel of serum biomarkers differentiates IgA nephropathy from other renal diseases. PLoS One 2014;9:e98081. 


\section{Kidney \\ Blood Pressure Research}

Kidney Blood Press Res 2014;39:450-489

\begin{tabular}{l|l}
\hline DOI: $10.1159 / 000368458$ & (c 2014 S. Karger AG, Basel \\
\hline
\end{tabular}

Publisned ontIne: November 30, 2014

www.karger.com/kbr

-34 Yamaji K, Kurusu A, Okamoto M, Sekiguchi Y, Horikoshi S, Tomino Y: Effect of educational hospitalization on chronic kidney disease (CKD) patients. Clin Nephrol 2007;68:401-404.

35 Kobayashi T, Yamaji K, Takeda Y, Maiguma M, Omote K, Sekiguchi Y, Tsuge T, Shimizu Y, Suzuki Y, Ohsawa I, Kurusu A, Hamada C, Horikoshi S, Tomino Y: Efficacy of educational short-term hospitalization in patients with chronic kidney disease (CKD): Second report. . Nephrol Frontier (Jap) 2011;10:94-98.

-36 Tomino Y, Kawamura T, Kimura K, Endoh M, Hosoya T, Horikoshi S, Utsunomiya Y, Yasuda T, Toyoda M, Tsuge T, Kaneko K: Antiproteinuric effect of olmesartan in patients with IgA nephropathy. J Nephrol 2009;22:224-231.

-37 Hayashi K, Wakino S, Sugano N, Ozawa Y, Homma K, Saruta T: Ca2+ channel subtypes and pharmacology in the kidney. Circ Res 2007;100:342-353.

38 Takenaka T, Takane H, Okada H, Ohno Y, Suzuki H: Long-term effects of calcium antagonists on augmentation index in hypertensive patients with chronic kidney diseases. NDT Plus 2009;2:192-193.

-39 Tomino Y, Shimizu Y, Hamada C, Kurusu A, Ohsawa I, Suzuki Y, Tsuge T, Io H, Kobayashi N, Takeda Y, Asanuma K, Tanaka Y, Suzuki H, Nakata J, Takara K, Horikoshi S: One-year results of an open-label study on antiproteinuric effect of benidipine in elderly patients with chronic kidney disease. J Nephrol 2011;24:756763.

40 Kobayashi Y, Hiki Y, Kokubo T, Horii A, Tateno S: Steroid therapy during the early stage of progressive IgA nephropathy. A 10-year follow-up study. Nephron 1996;72:237-242.

41 Tomino Y, Suzuki H, Horikoshi S, Imai E, Miyazaki M, Ohzono Y, Harada T, Yoshida H, Kawamura T, Kobayashi Y, Suzuki S, Nitta K, Hotta O, Yoshikwa N, Endoh M, Sakai H: Multicenter trial of adrenocorticosteroids in Japanese patients with IgA nephropathy- results of the special study group ( IgA nephropathy) on progressive glomerular disease, Ministry of Health, Labor and Welfare of Japan. Curr Topics Steroid Res 2004;4:93-98.

-42 Hotta O, Miyazaki M, Furuta T, Tomioka S, Chiba S, Horigome I, Abe K, Taguma Y: Tonsillectomy and steroid pulse therapy significantly impact on clinical remission in patients with IgA nephropathy. Am J Kidney Dis 2001;38:736-743.

-43 Miura N, Imai H, Kikuchi S, Hayashi S, Endoh M, Kawamura T, Tomino Y, Moriwaki K, Kiyomoto H, Kohagura K, Nakazawa E, Kusano E, Mochizuki T, Nomura S, Sasaki T, Kashihara N, Soma J, Tomo T, Nakabayashi I, Yoshida M, Watanabe T: Tonsillectomy and steroid pulse (TSP) therapy for patients with IgA nephropathy: a nationwide survey of TSP therapy in Japan and an analysis of the predictive factors for resistance to TSP therapy. Clin Exp Nephrol 2009;13:460-466.

-44 Sato D, Suzuki Y, Kano T, Suzuki H, Matsuoka J, Yokoi H, Horikoshi S, Ikeda K, Tomino Y: Tonsillar TLR9 expression and efficacy of tonsillectomy with steroid pulse therapy in IgA nephropathy patients. Nephrol Dial Transplant 2012;27:1090-1097.

45 Kawamura T, Yoshimura M, Miyazaki Y, Okamoto H, Kimura K, Hirano K, Matsushima M, Utsunomiya Y, Ogura M, Yokoo T, Okonogi H, Ishii T, Hamaguchi A, Ueda H, Furusu A, Horikoshi S, Suzuki Y, Shibata T, Yasuda T, Shirai S, Imasawa T, Kanozawa K, Wada A, Yamaji I, Miura N, Imai H, Kasai K, Soma J, Fujimoto S, Matsuo S, Tomino Y, Special Ig ANSG: A multicenter randomized controlled trial of tonsillectomy combined with steroid pulse therapy in patients with immunoglobulin A nephropathy. Nephrol Dial Transplant 2014;29:1546-1553.

46 Nakata J, Suzuki Y, Suzuki H, Sato D, Kano T, Yanagawa H, Matsuzaki K, Horikoshi S, Novak J, Tomino Y: Changes in nephritogenic serum galactose-deficient IgA1 in IgA nephropathy following tonsillectomy and steroid therapy. PLoS One 2014;9:e89707.

-47 Suzuki Y, Matsuzaki K, Suzuki H, Sakamoto N, Joh K, Kawamura T, Tomino Y, Matsuo S: Proposal of remission criteria for IgA nephropathy. Clin Exp Nephrol 2014;18:481-486.

-48 Koyama A, Igarashi M, Kobayashi M: Natural history and risk factors for immunoglobulin A nephropathy in Japan. Research Group on Progressive Renal Diseases. Am J Kidney Dis 1997;29:526-532.

49 Goto M, Wakai K, Kawamura T, Ando M, Endoh M, Tomino Y: A scoring system to predict renal outcome in IgA nephropathy: a nationwide 10-year prospective cohort study. Nephrol Dial Transplant 2009;24:30683074.

50 Gohda T, Tomino Y: A paradigm shift for the concept of diabetic nephropathy. Juntendo Med J 2014, in press.

51 Araki S: APOE polymorphism and diabetic nephropathy. Clin Exp Nephrol 2014;18:230-233. 


\section{Kidney \\ Blood Pressure Research}

Kidney Blood Press Res 2014;39:450-489

\begin{tabular}{l|l}
\hline DOI: $10.1159 / 000368458$ & (C) 2014 S. Karger AG, Basel
\end{tabular}

Published onIIne: November 30, 2014

www.karger.com/kbr

Tomino: Clinicopathology of Chronic Kidney Disease (CKD)

52 Horikoshi S, Higurashi A, Kaneko E, Yoshimura H, Ohsawa I, Suzuki Y, Hamada C, Tomino Y: A new screening method for proteinuria using Erythrosin B and an automated analyzer-rapid, sensitive and inexpensive determination. Clin Chim Acta 2012;413:1087-1091.

53 Horikoshi S, Okuda M, Nishimura E, Ohsawa I, Suzuki Y, Shimizu Y, Hamada C, Tomino Y: Usefulness of HPLC assay for early detection of microalbuminuria in chronic kidney disease. J Clin Lab Anal 2013;27:333-338.

54 Iijima T, Suzuki S, Sekizuka K, Hishiki T, Yagame M, Jinde K, Saotome N, Suzuki D, Sakai H, Tomino Y: Followup study on urinary type IV collagen in patients with early stage diabetic nephropathy. J Clin Lab Anal 1998;12:378-382.

55 Tomino Y, Suzuki S, Azushima C, Shou I, Iijima T, Yagame M, Wang LN, Chen HC, Lai KN, Tan SY, Kim MJ: Asian multicenter trials on urinary type IV collagen in patients with diabetic nephropathy. J Clin Lab Anal 2001;15:188-192.

-56 Tashiro K, Koyanagi I, Saitoh A, Shimizu A, Shike T, Ishiguro C, Koizumi M, Funabiki K, Horikoshi S, Shirato I, Tomino Y: Urinary levels of monocyte chemoattractant protein-1 (MCP-1) and interleukin-8 (IL-8), and renal injuries in patients with type 2 diabetic nephropathy. J Clin Lab Anal 2002;16:1-4.

57 Murakoshi M, Gohda T, Tanimoto M, Funabiki K, Horikoshi S, Tomino Y: Role of mindin in diabetic nephropathy. Exp Diabetes Res 2011;2011:486305.

58 Murakoshi M, Tanimoto M, Gohda T, Hagiwara S, Takagi M, Horikoshi S, Tomino Y: Mindin: a novel marker for podocyte injury in diabetic nephropathy. Nephrol Dial Transplant 2011;26:2153-2160.

59 Barrett AJ, Davies ME, Grubb A: The place of human gamma-trace (cystatin C) amongst the cysteine proteinase inhibitors. Biochem Biophys Res Commun 1984;120:631-636.

60 Shimizu-Tokiwa A, Kobata M, Io H, Kobayashi N, Shou I, Funabiki K, Fukui M, Horikoshi S, Shirato I, Saito $\mathrm{K}$, Tomino Y: Serum cystatin $\mathrm{C}$ is a more sensitive marker of glomerular function than serum creatinine. Nephron 2002;92:224-226.

61 Tomino Y, Suzuki S, Gohda T, Kobayashi M, Horikoshi S, Imai H, Saito T, Kawamura T, Yorioka N, Harada T, Yasumoto Y, Kida H, Kobayashi Y, Endoh M, Sato H, Saito K: Serum cystatin C may predict the prognostic stages of patients with IgA nephropathy prior to renal biopsy. J Clin Lab Anal 2001;15:25-29.

62 Shimizu A, Horikoshi S, Rinnno H, Kobata M, Saito K, Tomino Y: Serum cystatin C may predict the early prognostic stages of patients with type 2 diabetic nephropathy. J Clin Lab Anal 2003;17:164-167.

63 Locksley RM, Killeen N, Lenardo MJ: The TNF and TNF receptor superfamilies: integrating mammalian biology. Cell 2001;104:487-501.

64 Gohda T, Tomino Y: Novel biomarkers for the progression of diabetic nephropathy: soluble TNF receptors. Curr Diab Rep 2013;13:560-566.

65 Omote K, Gohda T, Murakoshi M, Sasaki Y, Kazuno S, Fujimura T, Ishizaka M, Sonoda Y, Tomino Y: Role of the TNF pathway in the progression of diabetic nephropathy in KK-A(y) mice. Am J Physiol Renal Physiol 2014;306:F1335-1347.

66 Friedman EA: Advanced glycation end-products in diabetic nephropathy. Nephrol Dial Transplant 1999;14:1-9.

67 Niewczas MA, Gohda T, Skupien J, Smiles AM, Walker WH, Rosetti F, Cullere X, Eckfeldt JH, Doria A, Mayadas TN, Warram JH, Krolewski AS: Circulating TNF receptors 1 and 2 predict ESRD in type 2 diabetes. J Am Soc Nephrol 2012;23:507-515.

68 Vlassara H, Striker LJ, Teichberg S, Fuh H, Li YM, Steffes M: Advanced glycation end products induce glomerular sclerosis and albuminuria in normal rats. Proc Natl Acad Sci USA 1994;91:11704-11708.

69 Suzuki D, Miyata T, Kurokawa K: Carbonyl stress. Contrib Nephrol 2001;36-45.

70 Yamagishi S, Takeuchi M, Makita Z: Advanced glycation end products and the pathogenesis of diabetic nephropathy. Contrib Nephrol 2001;30-35.

71 Shou I, Fukui M, Tomino Y: Efficacy of ACE inhibitor (captopril) on glomerular antioxidant enzyme activity and hypertension in diabetic hypertensive rats. Contrib Nephrol 2001;74-78.

72 Tanaka M, Suzuki Y, Shirato I, Takahara H, Shibata T, Sugaya T, Shimamoto K, Horikoshi S, Tomino Y: Tubular epithelial cells have the capacity to transdifferentiate into CD68-positive macrophage-like cells by oxidative stress. Inflamm Res 2008;57:593-600.

73 Jenkins AJ, Lyons TJ, Zheng D, Otvos JD, Lackland DT, McGee D, Garvey WT, Klein RL, Group DER: Lipoproteins in the DCCT/EDIC cohort: associations with diabetic nephropathy. Kidney Int 2003;64:817828. 


\section{Kidney \\ Blood Pressure Research}

Kidney Blood Press Res 2014;39:450-489

\begin{tabular}{l|l}
\hline DOI: $10.1159 / 000368458$ & (c) 2014 S. Karger AG, Basel
\end{tabular}

Publisned online: November 30, 2014

www.karger.com/kbr

Tomino: Clinicopathology of Chronic Kidney Disease (CKD)

74 Toyama T, Shimizu M, Furuichi K, Kaneko S, Wada T: Treatment and impact of dyslipidemia in diabetic nephropathy. Clin Exp Nephrol 2014;18:201-205.

75 Kondo K, Nozawa K, Tomita T, Ezaki K: Inbred strains resulting from Japanese Mice. Bull Exp Animal 1957;6:107-112.

76 Nishimura M: Breeding of mice strains for diabetes mellitus. Exp Animal 1969;18:147-157.

77 Ito T, Tanimoto M, Yamada K, Kaneko S, Matsumoto M, Obayashi K, Hagiwara S, Murakoshi M, Aoki T, Wakabayashi M, Gohda T, Funabiki K, Maeda K, Horikoshi S, Tomino Y: Glomerular changes in the KK-Ay/Ta mouse: a possible model for human type 2 diabetic nephropathy. Nephrology (Carlton) 2006;11:29-35.

-78 Aoki T, Kaneko S, Tanimoto M, Gohda T, Hagiwara S, Murakoshi M, Ishikawa Y, Furukawa M, Funabiki K, Horikoshi S, Tomino Y: Identification of quantitative trait loci for diabetic nephropathy in KK-Ay/Ta mice. J Nephrol 2012;25:127-136.

79 Mooyaart AL: Genetic associations in diabetic nephropathy. Clin Exp Nephrol 2014;18:197-200.

-80 Macedo CS, Lerco MM, Capelletti SM, Silva RJ, Pinheiro Dde 0, Spadella CT: Reduction of podocytes number in late diabetic alloxan nephropathy: prevention by glycemic control. Acta Cir Bras 2007;22:337-341.

81 Ishikwa Y, Ito T, Tanimoto M, Hagiwara S, Furukawa M, Yamaguchi S, Omote K, Asanuma K, Gohda T, Shimizu Y, Funabiki K, Horikoshi S, Tomino Y: Podocyte loss and albuminuria of KK-Ay mouse: A spontaneous animal model for human type 2 diabetic nephropathy. J Diab Mellitus 2012;2:346-352.

82 Gu L, Hagiwara S, Fan Q, Tanimoto M, Kobata M, Yamashita M, Nishitani T, Gohda T, Ni Z, Qian J, Horikoshi S, Tomino Y: Role of receptor for advanced glycation end-products and signalling events in advanced glycation end-product-induced monocyte chemoattractant protein-1 expression in differentiated mouse podocytes. Nephrol Dial Transplant 2006;21:299-313.

83 Nakamura T, Ushiyama C, Suzuki S, Hara M, Shimada N, Ebihara I, Koide H: Urinary excretion of podocytes in patients with diabetic nephropathy. Nephrol Dial Transplant 2000;15:1379-1383.

84 Boor P, Celec P, Behuliak M, Grancic P, Kebis A, Kukan M, Pronayova N, Liptaj T, Ostendorf T, Sebekova K: Regular moderate exercise reduces advanced glycation and ameliorates early diabetic nephropathy in obese Zucker rats. Metabolism 2009;58:1669-1677.

-85 Ishikawa Y, Gohda T, Tanimoto M, Omote K, Furukawa M, Yamaguchi S, Murakoshi M, Hagiwara S, Horikoshi S, Funabiki K, Tomino Y: Effect of exercise on kidney function, oxidative stress, and inflammation in type 2 diabetic KK-A(y) mice. Exp Diabetes Res 2012;2012:702948.

-86 Khalifah RG, Baynes JW, Hudson BG: Amadorins: novel post-Amadori inhibitors of advanced glycation reactions. Biochem Biophys Res Commun 1999;257:251-258.

-87 Degenhardt TP, Alderson NL, Arrington DD, Beattie RJ, Basgen JM, Steffes MW, Thorpe SR, Baynes JW: Pyridoxamine inhibits early renal disease and dyslipidemia in the streptozotocin-diabetic rat. Kidney Int 2002;61:939-950.

-88 Tanimoto M, Gohda T, Kaneko S, Hagiwara S, Murakoshi M, Aoki T, Yamada K, Ito T, Matsumoto M, Horikoshi S, Tomino Y: Effect of pyridoxamine (K-163), an inhibitor of advanced glycation end products, on type 2 diabetic nephropathy in KK-A(y)/Ta mice. Metabolism 2007;56:160-167.

89 Murakoshi M, Tanimoto M, Gohda T, Hagiwara S, Ohara I, Toyoda H, Ishikawa Y, Horikoshi S, Tomino Y: Pleiotropic effect of pyridoxamine on diabetic complications via CD36 expression in KK-Ay/Ta mice. Diabetes Res Clin Pract 2009;83:183-189.

$\$ 90$ Chen HC, Guh JY, Shin SJ, Tomino Y, Lai YH: Effects of pravastatin on superoxide and fibronectin production of mesangial cells induced by low-density lipoprotein. Kidney Blood Press Res 2002;25:2-6.

\$1 Gu L, Ni Z, Qian J, Tomino Y: Pravastatin inhibits carboxymethyllysine-induced monocyte chemoattractant protein 1 expression in podocytes via prevention of signalling events. Nephron Exp Nephrol 2007;106:e110.

-92 Matsumoto M, Tanimoto M, Gohda T, Aoki T, Murakoshi M, Yamada K, Yamazaki T, Kaneko S, Horikoshi S, Tomino Y: Effect of pitavastatin on type 2 diabetes mellitus nephropathy in KK-Ay/Ta mice. Metabolism 2008;57:691-697.

93 Kimura K, Shimano H, Yokote K, Urashima M, Teramoto T: Effects of pitavastatin (LIVALO tablet) on the estimated glomerular filtration rate (eGFR) in hypercholesterolemic patients with chronic kidney disease. Sub-analysis of the LIVALO Effectiveness and Safety (LIVES) Study. J Atheroscler Thromb 2010;17:601-609. 


\section{Kidney \\ Blood Pressure Research}

\begin{tabular}{l|l}
\hline Kidney Blood Press Res 2014;39:450-489 \\
\hline \begin{tabular}{l|l} 
DOI: 10.1159/000368458 & (c) 2014 S. Karger AG, Basel \\
Publisned online: Tvovember 30, 2014 & wwrger.com/kbr
\end{tabular} \\
\hline
\end{tabular}

Tomino: Clinicopathology of Chronic Kidney Disease (CKD)

-94 Kimura S, Inoguchi T, Yokomizo H, Maeda Y, Sonoda N, Takayanagi R: Randomized comparison of pitavastatin and pravastatin treatment on the reduction of urinary albumin in patients with type 2 diabetic nephropathy. Diabetes Obes Metab 2012;14:666-669.

-95 Zhang M, Hagiwara S, Matsumoto M, Gu L, Tanimoto M, Nakamura S, Kaneko S, Gohda T, Qian J, Horikoshi S, Tomino Y: Effects of eicosapentaenoic acid on the early stage of type 2 diabetic nephropathy in KKA(y)/Ta mice: involvement of anti-inflammation and antioxidative stress. Metabolism 2006;55:1590-1598.

$\$ 96$ Hagiwara S, Makita Y, Gu L, Tanimoto M, Zhang M, Nakamura S, Kaneko S, Itoh T, Gohda T, Horikoshi S, Tomino Y: Eicosapentaenoic acid ameliorates diabetic nephropathy of type 2 diabetic KKAy/Ta mice: involvement of MCP-1 suppression and decreased ERK1/2 and p38 phosphorylation. Nephrol Dial Transplant 2006;21:605-615.

97 Shimizu H, Ohtani K, Tanaka Y, Sato N, Mori M, Shimomura Y: Long-term effect of eicosapentaenoic acid ethyl (EPA-E) on albuminuria of non-insulin dependent diabetic patients. Diabetes Res Clin Pract 1995;28:35-40.

98 Fan Q, Liao J, Kobayashi M, Yamashita M, Gu L, Gohda T, Suzuki Y, Wang LN, Horikoshi S, Tomino Y: Candesartan reduced advanced glycation end-products accumulation and diminished nitro-oxidative stress in type 2 diabetic KK/Ta mice. Nephrol Dial Transplant 2004;19:3012-3020.

-99 Yamazaki T, Tanimoto M, Gohda T, Ohara I, Hagiwara S, Murakoshi M, Matsumoto M, Kaneko S, Aoki T, Toyoda H, Ishikawa Y, Funabiki K, Horikoshi S, Tomino Y: Combination effects of enalapril and losartan on lipid peroxidation in the kidneys of KK-Ay/Ta mice. Nephron Exp Nephrol 2009;113:e66-76.

100 Fried LF, Emanuele N, Zhang JH, Brophy M, Conner TA, Duckworth W, Leehey DJ, McCullough PA, O'Connor T, Palevsky PM, Reilly RF, Seliger SL, Warren SR, Watnick S, Peduzzi P, Guarino P, Investigators VN-D: Combined angiotensin inhibition for the treatment of diabetic nephropathy. N Engl J Med 2013;369:18921903.

101 Furukawa M, Gohda T, Hagiwara S, Tanimoto M, Horikoshi S, Funabiki K, Tomino Y: Effect of the direct renin inhibitor aliskiren on urinary albumin excretion in spontaneous type 2 diabetic KK-A (y) mouse. Int J Nephrol 2013;2013:519130.

102 Parving HH, Persson F, Lewis JB, Lewis EJ, Hollenberg NK, Investigators AS: Aliskiren combined with losartan in type 2 diabetes and nephropathy. N Engl J Med 2008;358:2433-2446.

103 Benter IF, Yousif MH, Cojocel C, Al-Maghrebi M, Diz DI: Angiotensin-(1-7) prevents diabetes-induced cardiovascular dysfunction. Am J Physiol Heart Circ Physiol 2007;292:H666-672.

104 Brosnihan KB, Li P, Ferrario CM: Angiotensin-(1-7) dilates canine coronary arteries through kinins and nitric oxide. Hypertension 1996;27:523-528.

105 Moon JY, Tanimoto M, Gohda T, Hagiwara S, Yamazaki T, Ohara I, Murakoshi M, Aoki T, Ishikawa Y, Lee SH, Jeong KH, Lee TW, Ihm CG, Lim SJ, Tomino Y: Attenuating effect of angiotensin-(1-7) on angiotensin IImediated NAD(P)H oxidase activation in type 2 diabetic nephropathy of KK-A(y)/Ta mice. Am J Physiol Renal Physiol 2011;300:F1271-1282.

106 Ohara I, Tanimoto M, Gohda T, Yamazaki T, Hagiwara S, Murakoshi M, Aoki T, Toyoda H, Ishikawa Y, Funabiki K, Horikoshi S, Tomino Y: Effect of combination therapy with angiotensin receptor blocker and 1,25-dihydroxyvitamin D(3) in type 2 diabetic nephropathy in KK-A(y)/Ta mice. Nephron Exp Nephrol 2011;117:e124-132.

107 Hamada C, Tomino Y: Histological alterations in peritonela dialysis. Juntendo Med J 2014, in press.

108 Kaneko K, Hamada C, Tomino Y: Peritoneal fibrosis intervention. Perit Dial Int 2007;27:S82-86.

109 Io H, Hamada C, Ro Y, Ito Y, Hirahara I, Tomino Y: Morphologic changes of peritoneum and expression of VEGF in encapsulated peritoneal sclerosis rat models. Kidney Int 2004;65:1927-1936.

110 Ro Y, Hamada C, Io H, Hayashi K, Hirahara I, Tomino Y: Rapid, simple, and reliable method for the diagnosis of CAPD peritonitis using the new MMP-9 test kit. J Clin Lab Anal 2004;18:224-230.

111 Kanda R, Hamada C, Kaneko K, Nakano T, Wakabayashi K, Io H, Horikoshi S, Tomino Y: Pentraxin 3 as a new biomarker of peritoneal injury in peritoneal dialysis patients. J Artif Organs 2013;16:66-73.

112 Di Paolo N, Sacchi G, De Mia M, Gaggiotti E, Capotondo L, Rossi P, Bernini M, Pucci AM, Ibba L, Sabatelli P, et al.: Morphology of the peritoneal membrane during continuous ambulatory peritoneal dialysis. Nephron 1986;44:204-211.

113 Dobbie JW, Lloyd JK, Gall CA: Categorization of ultrastructural changes in peritoneal mesothelium, stroma and blood vessels in uremia and CAPD patients. Adv Perit Dial 1990;6:3-12. 


\section{Kidney \\ Blood Pressure Research}

Kidney Blood Press Res 2014;39:450-489

\begin{tabular}{l|l}
\hline DOI: $10.1159 / 000368458$ & C 2014 S. Karger AG, Basel
\end{tabular}

Publisned ontıne: November 30, 2014

www.karger.com/kbr

114 Twardowski ZJ: Clinical value of standardized equilibration tests in CAPD patients. Current Concepts of CAPD. Blood Purif 1989; 7:95-108.

115 Williams JD, Craig KJ, Topley N, Von Ruhland C, Fallon M, Newman GR, Mackenzie RK, Williams GT, Peritoneal Biopsy Study G: Morphologic changes in the peritoneal membrane of patients with renal disease. J Am Soc Nephrol 2002;13:470-479.

116 Honda K, Hamada C, Nakayama M, Miyazaki M, Sherif AM, Harada T, Hirano H, Peritoneal Biopsy Study Group of the Japanese Society for Peritoneal D: Impact of uremia, diabetes, and peritoneal dialysis itself on the pathogenesis of peritoneal sclerosis: a quantitative study of peritoneal membrane morphology. Clin J Am Soc Nephrol 2008;3:720-728.

117 Shimaoka T, Hamada C, Kaneko K, Io H, Sekiguchi Y, Aruga S, Inuma J, Inami Y, Hotta Y, Horikoshi S, Kumasaka T, Tomino Y: Quantitative evaluation and assessment of peritoneal morphologic changes in peritoneal dialysis patients. Nephrol Dial Transplant 2010;25:3379-3385.

118 Yokoyama K, Yoshida H, Matsuo N, Maruyama Y, Kawamura Y, Yamamoto R, Hanaoka K, Ikeda M, Yamamoto H, Nakayama M, Kawaguchi Y, Hosoya T: Serum beta2 microglobulin (beta2 MG) level is a potential predictor for encapsulating peritoneal sclerosis (EPS) in peritoneal dialysis patients. Clin Nephrol 2008;69:121-126.

119 Nakamoto H, Hamada C, Shimaoka T, Sekiguchi Y, Io H, Kaneko K, Horikoshi S, Tomino Y: Accumulation of advanced glycation end products and beta 2-microglobulin in fibrotic thickening of the peritoneum in longterm peritoneal dialysis patients. J Artif Organs 2014;17:60-68.

120 Osada S, Hamada C, Shimaoka T, Kaneko K, Horikoshi S, Tomino Y: Alterations in proteoglycan components and histopathology of the peritoneum in uraemic and peritoneal dialysis (PD) patients. Nephrol Dial Transplant 2009;24:3504-3512.

-121 Nakazato Y, Yamaji Y, Oshima N, Hayashi M, Saruta T: Calcification and osteopontin localization in the peritoneum of patients on long-term continuous ambulatory peritoneal dialysis therapy. Nephrol Dial Transplant 2002;17:1293-1303.

-122 Braun N, Alscher MD, Fritz P, Latus J, Edenhofer I, Reimold F, Alper SL, Kimmel M, Biegger D, Lindenmeyer M, Cohen CD, Wuthrich RP, Segerer S: The spectrum of podoplanin expression in encapsulating peritoneal sclerosis. PLoS One 2012; 7:e53382.

123 Ro Y, Hamada C, Inaba M, Io H, Kaneko K, Tomino Y: Inhibitory effects of matrix metalloproteinase inhibitor ONO-4817 on morphological alterations in chlorhexidine gluconate-induced peritoneal sclerosis rats. Nephrol Dial Transplant 2007;22:2838-2848.

124 Matsumoto M, Io H, Furukawa M, Okumura K, Masuda A, Seto T, Takagi M, Sato M, Nagahama L, Omote K, Hisada A, Horikoshi S, Tomino Y: Risk factors associated with increased left ventricular mass index in chronic kidney disease patients evaluated using echocardiography. J Nephrol 2012;25:794-801.

125 Io H, Ro Y, Sekiguchi Y, Shimaoka T, Inuma J, Hotta Y, Aruga S, Inami Y, Sato M, Kobayashi T, Masuda A, Kaneko K, Hamada C, Ohtaki E, Horikoshi S, Tomino Y: Cardiac function and structure in longitudinal analysis of echocardiography in peritoneal dialysis patients. Perit Dial Int 2010;30:353-361.

126 Ishii M, Ohsawa I, Inoshita H, Kusaba G, Onda K, Wakabayashi M, Ohi H, Horikoshi S, Matsushita M, Tomino Y: Serum concentration of complement components of the lectin pathway in maintenance hemodialysis patients, and relatively higher levels of L-Ficolin and MASP-2 in Mannose-binding lectin deficiency. Ther Apher Dial 2011;15:441-447.

127 Klein NJ: Mannose-binding lectin: do we need it? Mol Immunol 2005;42:919-924.

128 Thiel S, Frederiksen PD, Jensenius JC: Clinical manifestations of mannan-binding lectin deficiency. Mol Immunol 2006;43:86-96.

129 Sorensen R, Thiel S, Jensenius JC: Mannan-binding-lectin-associated serine proteases, characteristics and disease associations. Springer Semin Immunopathol 2005;27:299-319.

130 Dahl M, Tybjaerg-Hansen A, Schnohr P, Nordestgaard BG: A population-based study of morbidity and mortality in mannose-binding lectin deficiency. J Exp Med 2004;199:1391-1399.

131 Atkinson AP, Cedzynski M, Szemraj J, St Swierzko A, Bak-Romaniszyn L, Banasik M, Zeman K, Matsushita M, Turner ML, Kilpatrick DC: L-ficolin in children with recurrent respiratory infections. Clin Exp Immunol 2004;138:517-520. 


\section{Kidney \\ Blood Pressure Research}

\begin{tabular}{l|l}
\hline Kidney Blood Press Res 2014;39:450-489 \\
\hline DOI: 10.1159/000368458 & $\begin{array}{l}\text { C) 2014 S. Karger AG, Basel } \\
\text { www.karger.com/kbr }\end{array}$ \\
\hline Publisned onlme: November 30, 2014 &
\end{tabular}

Tomino: Clinicopathology of Chronic Kidney Disease (CKD)

132 Inoshita H, Ohsawa I, Kusaba G, Ishii M, Onda K, Horikoshi S, Ohi H, Tomino Y: Complement in patients receiving maintenance hemodialysis: functional screening and quantitative analysis. BMC Nephrol 2010;11:34.

133 Shimizu Y, Sonoda A, Nogi C, Ogushi Y, Kanda R, Yamaguchi S, Nohara N, Aoki T, Yamada K, Nakata J, Io H, Kurusu A, Hamada C, Horikoshi S, Tomino Y: B-type (brain) natriuretic peptide and pruritus in hemodialysis patients. Int J Nephrol Renovasc Dis 2014;7:329-335.

134 Io H, Matsumoto M, Okumura K, Sato M, Masuda A, Furukawa M, Nohara N, Tanimoto M, Kodama F, Hagiwara S, Gohda T, Shimizu Y, Tomino Y: Predictive factors associated with left ventricular hypertrophy at baseline and in the follow-up period in non-diabetic hemodialysis patients. Semin Dial 2011;24:349-354.

135 Furukawa M, Io H, Tanimoto M, Hagiwara S, Horikoshi S, Tomino Y: Predictive factors associated with the period of time before initiation of hemodialysis in CKD stages 4 and 5. Nephron Clin Pract 2011;117:c341347.

136 Nakatani T, Naganuma T, Masuda C, Sugimura T, Uchida J, Takemoto Y, Sugimura K: The prognostic role of atrial natriuretic peptides in hemodialysis patients. Blood Purif 2003;21:395-400.

-137 Tsang TS, Barnes ME, Gersh BJ, Takemoto Y, Rosales AG, Bailey KR, Seward JB: Prediction of risk for first age-related cardiovascular events in an elderly population: the incremental value of echocardiography. J Am Coll Cardiol 2003;42:1199-1205.

138 Foley RN, Parfrey PS, Morgan J, Barre PE, Campbell P, Cartier P, Coyle D, Fine A, Handa P, Kingma I, Lau CY, Levin A, Mendelssohn D, Muirhead N, Murphy B, Plante RK, Posen G, Wells GA: Effect of hemoglobin levels in hemodialysis patients with asymptomatic cardiomyopathy. Kidney Int 2000;58:1325-1335.

139 Jeren-Struji'c B, Raos V, Jeren T, Horvatin-Godler S: Morphologic and functional changes of left ventricle in dialyzed patients after treatment with recombinant human erythropoietin (r-HuEPO). Angiology 2000;51:131-139.

$>140$ Levin A, Djurdjev O, Barrett B, Burgess E, Carlisle E, Ethier J, Jindal K, Mendelssohn D, Tobe S, Singer J, Thompson C: Cardiovascular disease in patients with chronic kidney disease: getting to the heart of the matter. Am J Kidney Dis 2001;38:1398-1407.

141 Huting J, Kramer W, Schutterle G, Wizemann V: Analysis of left-ventricular changes associated with chronic hemodialysis. A noninvasive follow-up study. Nephron 1988;49:284-290.

142 Laukkanen JA, Kurl S, Eranen J, Huttunen M, Salonen JT: Left atrium size and the risk of cardiovascular death in middle-aged men. Arch Intern Med 2005;165:1788-1793.

143 Chan CT, Floras JS, Miller JA, Richardson RM, Pierratos A: Regression of left ventricular hypertrophy after conversion to nocturnal hemodialysis. Kidney Int 2002;61:2235-2239.

144 Chan CT, Harvey PJ, Picton P, Pierratos A, Miller JA, Floras JS: Short-term blood pressure, noradrenergic, and vascular effects of nocturnal home hemodialysis. Hypertension 2003;42:925-931.

145 Nagano M, Higaki J, Mikami H, Nakamaru M, Higashimori K, Katahira K, Tabuchi Y, Moriguchi A, Nakamura F, Ogihara T: Converting enzyme inhibitors regressed cardiac hypertrophy and reduced tissue angiotensin II in spontaneously hypertensive rats. J Hypertens 1991;9:595-599. 